\title{
Presynaptic NCAM Is Required for Motor Neurons to Functionally Expand Their Peripheral Field of Innervation in Partially Denervated Muscles
}

\author{
Peter H. Chipman, ${ }^{1}$ Melitta Schachner, ${ }^{4}$ and Victor F. Rafuse ${ }^{1,2,3}$ \\ Departments of ${ }^{1}$ Medical Neuroscience and ${ }^{2}$ Medicine (Neurology), Dalhousie University, Halifax, Nova Scotia B3H 1 X5, Canada, ${ }^{3}$ Brain Repair Centre, Life \\ Science Research Institute, Halifax, Nova Scotia B3H 4H7, Canada, and ${ }^{4}$ Keck Center for Collaborative Neuroscience, Rutgers University, Piscataway, New \\ Jersey 08854-8082
}

\begin{abstract}
The function of neural cell adhesion molecule (NCAM) expression in motor neurons during axonal sprouting and compensatory reinnervation was explored by partially denervating soleus muscles in mice lacking presynaptic NCAM $\left(H b 9^{c r e} N C A M^{f l x}\right)$. In agreement with previous studies, the contractile force of muscles in wild-type $\left(N C A M^{+/+}\right)$mice recovered completely 2 weeks after $75 \%$ of the motor innervation was removed because motor unit size increased by 2.5 times. In contrast, similarly denervated muscles in $H b 9^{c r e} N C A M^{f l x}$ mice failed to recover the force lost due to the partial denervation because motor unit size did not change. Anatomical analysis indicated that $50 \%$ of soleus end plates were completely denervated $1-4$ weeks post-partial denervation in $H b 9^{c r e} N C A M^{f l x}$ mice, while another $25 \%$ were partially reinnervated. Synaptic vesicles (SVs) remained at extrasynaptic regions in $H b 9^{c r e} N C A M^{f l x}$ mice rather than being distributed, as occurs normally, to newly reinnervated neuromuscular junctions (NMJs). Electrophysiological analysis revealed two populations of $\mathrm{NMJs}$ in partially denervated $H b 9^{c r e} N C A M^{f l x}$ soleus muscles, one with high (mature) quantal content, and another with low (immature) quantal content. Extrasynaptic SVs in $H b 9^{c r e} N C A M^{f l x}$ sprouts were associated with L-type voltage-dependent calcium channel (L-VDCC) immunoreactivity and maintained an immature, L-VDCC-dependent recycling phenotype. Moreover, acute nifedipine treatment potentiated neurotransmission at newly sprouted NMJs, while chronic intraperitoneal treatment with nifedipine during a period of synaptic consolidation enhanced functional motor unit expansion in the absence of presynaptic NCAM. We propose that presynaptic NCAM bridges a critical link between the SV cycle and the functional expansion of synaptic territory through the regulation of L-VDCCs.
\end{abstract}

Key words: NCAM; neuromuscular junction; partial denervation; regeneration; sprouting

\section{Introduction}

Synaptic plasticity maintains appropriate circuit function in response to altered activity or functional milieu. These changes range from local adjustments in synaptic strength (Branco et al., 2008; Béique et al., 2011) to widespread reorganization of axonal terminal fields (Brown and Ironton, 1978; Rochel and Robbins, 1988; Schaefer et al., 2005). An example of large-scale synaptic reorganization occurs in skeletal muscles partially denervated by injury (Brown and Ironton, 1978; Rochel and Robbins, 1988; Rafuse et al., 1992). Favorable outcomes of partially denervated muscles require directed growth of axonal sprouts along Schwann

Received Feb. 18, 2014; revised June 3, 2014; accepted June 20, 2014.

Author contributions:P.H.C. and V.F.R. designed research;P.H.C. performed research; M.S. and V.F.R. contributed unpublished reagents/analytic tools; P.H.C., M.S., and V.F.R. analyzed data; P.H.C., M.S., and V.F.R. wrote the paper.

This work was supported by Grant 108413 from the Canadian Institutes for Health Research (to V.F.R.).P.H.C. was funded by a graduate student scholarship award from the Natural Sciences and Engineering Research Council of Canada. We thank Simone Laforest for her excellent technical assistance genotyping the mice. The SV2 antibody was obtained from the Developmental Studies Hybridoma Bank under the auspices of the National Institute of Child Health and Human Development and maintained by the University of lowa Department of Biology.

Correspondence should be addressed to Dr. Victor F. Rafuse, Department of Medical Neuroscience, Sir Charles

Tupper Medical Building, Dalhousie University, Halifax, NS B3H 1X5, Canada. E-mail: vrafuse@dal.ca.

P.H. Chipman's present address: RIKEN Brain Science Institute, Wako, Saitama 351-0198, Japan.

DOI:10.1523/JNEUROSCI.0697-14.2014

Copyright $\odot 2014$ the authors $\quad 0270-6474 / 14 / 3410497-14 \$ 15.00 / 0$ cell bridges that extend from innervated end plates to denervated synapses (Son and Thompson, 1995), the accumulation of synaptic resources at newly formed terminals, and the stabilization of neurotransmission at reinnervated sites (Rochel and Robbins, 1988; Schaefer et al., 2005). Failure to establish any one of these processes hinders functional recovery, and their malfunction may underlie some of the pathophysiology associated with motor neuron diseases such as amyotrophic lateral sclerosis (ALS; Gordon et al., 2004; Fischer and Glass, 2007).

The sprouting capacity of a single motor neuron is determined by its growth potential and its ability to maintain effective neurotransmission across supernumerary synapses (Rochel and Robbins, 1988; Rafuse et al., 1992). Healthy motor neurons in partially denervated muscles can sprout and expand their field of innervation to form motor units (MUs) four to five times their original size (Rafuse et al., 1992). The sprouting capacity of motor neurons afflicted with ALS, however, is significantly less (MilnerBrown et al., 1974; Dengler et al., 1990; Schmied et al., 1999; Hegedus et al., 2008). The reason for this attenuated sprouting response is unknown, in part because the mechanisms enabling effective transmission at synapses in expanded terminal fields are poorly understood. 
Table 1. Primary antibodies

\begin{tabular}{|c|c|c|c|c|}
\hline Antiserum & Host species & Dilution & Clonality & Source \\
\hline Dihydropyridine receptor ( $\alpha 2$ subunit, L-VDCC) & Mouse & $1: 500$ & Monoclonal & Sigma, St. Louis, MO \\
\hline NCAM (CD56) & Mouse & $1: 2000$ & Monoclonal & BD Biosciences, Franklin Lakes, NJ \\
\hline SV2 & Mouse & $1: 50$ & Monoclonal & Developmental Studies Hybridoma Bank, lowa City, IA \\
\hline Pan-axonal neurofilament (SMI-312) & Mouse & $1: 250$ & Monoclonal & Covance, Hornby, ON, Canada \\
\hline Synaptophysin & Rabbit & $1: 500$ & Polyclonal & Zymed, San Fransisco, CA \\
\hline
\end{tabular}

Cell adhesion molecules are potent regulators of synaptic stability and strongly influence neurotransmission (Polo-Parada et al., 2001; Vitureira et al., 2012). For example, neural cell adhesion molecule (NCAM) promotes synaptic stability by managing the distribution of presynaptic structures at developing and regenerating synapses (Rafuse et al., 2000; Sytnyk et al., 2002; Hata et al., 2007; Chipman et al., 2010; Enriquez-Barreto et al., 2012; Chattopadhyaya et al., 2013). As such, reinnervated neuromuscular junctions (NMJs) become weak, and ultimately degenerate after a peripheral nerve injury in NCAM-null mice (Chipman et al., 2010). This phenomenon also occurs at NMJs in Drosophila larvae lacking the NCAM homolog FasII (Schuster et al., 1996).

Here, we assessed the role of presynaptic NCAMs in regulating the functional expansion of MUs in partially denervated muscles after a partial nerve injury. We show that the recovery of contractile force was severely limited in mice lacking presynaptic NCAMs, in part because cycling synaptic vesicles (SVs) were not distributed to the sprouted nerve terminals normally. The recovery of force and the distribution of SVs became normal in mice lacking presynaptic NCAMs when they were administered the L-type voltage-dependent calcium channel (L-VDCC) antagonist nifedipine. These findings identify a function of presynaptic NCAMs in the regenerative reorganization of axon arbors and highlight a potential means to enhance sprouting of diseased neurons using pharmacological intervention.

\section{Materials and Methods}

Mice. Three different strains of mice of either sex were used in this study. $\mathrm{Hb}^{\mathrm{cre} /{ }^{+}}:: \mathrm{NCAM}^{\mathrm{flx} / \mathrm{flx}}$ mice (designated throughout as $\mathrm{Hb}^{\text {cre }} N C A M^{f l x}$ ), which lack NCAMs in motor neurons, were generated by breeding NCAM-floxed (NCAM ${ }^{\mathrm{fl} / \mathrm{flx}}$ ) mice (Bukalo et al., 2004) with mice expressing cre-recombinase under control of the $\mathrm{Hb} 9$ promoter (Yang et al., 2001). $\mathrm{HSA}^{\mathrm{cre} /+}:: \mathrm{NCAM}^{\mathrm{fl} / \mathrm{flx}}$ mice (designated throughout as $H S A^{c r e} N C A M^{f l x}$ ), which lack NCAMs on muscle fibers, were generated by crossing $\mathrm{NCAM}^{\mathrm{flx} / \mathrm{flx}}$ mice with mice expressing cre-recombinase under control of the HSA promoter (Miniou et al., 1999). Wild-type control mice (designated $N C A M^{+/+}$throughout) were cre-negative littermates of $H b 9^{c r e} N C A M^{f l x}$ and $H S A^{c r e} N C A M^{f l x}$ mice. All procedures were conducted in accordance to the guidelines of the Canadian Council on Animal Care and the policies of Dalhousie University.

Partial denervation surgery and motor neuron back-labeling procedures. All surgeries were performed on 3- to 5-month-old adult mice. Animals were anesthetized with isoflurane (Baxter), and a small incision was made in the skin in the dorsomedial aspect of the thorax. An incision was made in the fascia overlying the superior iliac crest, and spinal muscles were separated to visualize the L4-S1 transverse spinous processes. The L5 spinous process was removed, and the L5 root was carefully separated from surrounding tissue and ligated with a suture (10-0) prior to being cut to prevent regeneration. In some animals, a second procedure was performed to back-label motor neurons immediately following the L5 root transection. A small incision was made in the skin overlaying the dorsal shank muscles. The soleus muscle was exposed, and $<0.5 \mu$ l of $1 \%$ cholera toxin subunit b (CTB) conjugated with Alexa Fluor 594 or 488 (C22842; Invitrogen) was injected into either the ipsilateral or contralateral soleus muscle near the nerve entry point. A second surgery was performed in a subset of animals, as described previously (Chipman et al., 2010). Briefly, a small incision was made in the skin above the dorsal aspect of the knee to expose the tibial nerve, which was crushed two times consecutively $10 \mathrm{~mm}$ distal to its divergence from the sciatic nerve. Denervation was visually confirmed by noting muscle contraction and subsequent transparency of the nerve at the crush site.

Ex vivo isometric tension recordings. Mice were killed, and their right hindlimb was quickly dissected and placed into ice-cold, carbogenated (95\% $\mathrm{O}_{2}$ and $5 \% \mathrm{CO}_{2}$ ) Tyrode's solution containing the following (in $\mathrm{mm}$ ): $\mathrm{NaCl} 125, \mathrm{NaHCO}_{3} 24, \mathrm{KCl} 5.37, \mathrm{MgCl}_{2} 1, \mathrm{CaCl}_{2}, 1.8$, and dextrose 27.75. The soleus muscle and nerve supply were isolated and cut free at the insertion points on the femur and calcaneous bones. The proximal muscle tendon was securely pinned down on a Sylgard (Dow Corning)coated recording chamber that was perfused with carbogenated Tyrode's solution at room temperature. A suture $(2-0)$ was tied to the distal tendon and connected to a force transducer (FT 03; Grass Technologies). A fine-tipped polyethylene stimulating suction electrode (PE-190; Clay Adams) was used to deliver electrical current to the soleus nerve via an S88 stimulator (Grass Technologies) that was isolated from the ground using a stimulus isolation unit (PSIU6; Grass Technologies). Monophasic electrical stimuli $(0.05 \mathrm{~ms})$ were used to elicit maximal isometric contractions that were acquired at $10 \mathrm{kHz}$ using a Digidata $1322 \mathrm{~A}$ analog-to-digital board and Axoscope version 9.2 software (Molecular Devices)

Intracellular muscle fiber electrophysiology and the estimation of binomial statistics. Intracellular muscle fiber recordings were performed on unoperated, partially denervated, or completely reinnervated soleus muscles in carbogenated Tyrode's solution, as described above (Rafuse et al., 2000; Chipman et al., 2010). $\mu$-Contoxin GIIIB (5 $\mu \mathrm{M}$; Alomone Labs) was added to the bath to block postsynaptic muscle contraction via inhibition of muscle $\mathrm{Na}^{+}$channels. In some indicated experiments, nifedipine (50 $\mu \mathrm{M}$; Sigma) and $\omega$-agatoxin IVA (ATX) (100 nM; Alomone Labs) were sequentially applied to the recording chamber.

The application of binomial statistics to the estimation of neuromuscular transmission was performed as described previously (del Castillo and Katz, 1954a,b; Martin, 1955; Searl and Silinsky, 2003). Briefly, recorded end-plate potentials (EPPs) were corrected for nonlinear summation (McLachlan and Martin, 1981) and quantal contents $(m)$ were calculated as the ratio of the corrected mean end-plate potentials generated at $1 \mathrm{~Hz}$ to the mean miniature end-plate potential amplitude of that synapse.

Immunofluorescence and imaging. For ex vivo immunofluorescence, soleus muscles were pinned at physiological length, fixed for $20 \mathrm{~min}$ in $4 \%$ paraformaldehyde/PBS, and then teased into bundles of $\sim 20-40$ muscle fibers. Fibers were incubated in $0.1 \mathrm{M}$ glycine for $1 \mathrm{~h}$ and washed in PBS, then incubated overnight at room temperature in cocktails of primary antibodies, as described in Table 1. Muscle fibers were then washed in PBS and incubated for $1 \mathrm{~h}$ in a corresponding cocktail of secondary antibodies, which included either goat anti-mouse or goat anti-rabbit Alexa Fluor 488 or Alexa Fluor 647 (1:500; Invitrogen). All antibodies were applied in the presence of $10 \%$ blocking solution and $0.3 \%$ Triton X-100/PBS. Some cells were incubated in a PBS solution containing tetramethylrhodamine-conjugated $\alpha$-bungarotoxin ( $\alpha$-BTX; 1:500; Invitrogen) for $1 \mathrm{~h}$ at room temperature to label AChRs. Tissues were washed in PBS and mounted in a 50\% glycerol/PBS mixture containing $0.03 \mathrm{mg} / \mathrm{ml} \rho$-phenylenediamine. Colocalization analysis was performed using Zeiss Zen software on single optical sections $(0.5 \mu \mathrm{m})$.

End-plate analysis and classification of innervation type. For quantification of end-plate morphology and synaptic vesicle immunofluorescence, muscle fibers were digitally photographed using a wide-field fluorescence microscope equipped with a broad focal plane lens (Leica Microsystems) 
attached to a digital camera (C4742; Hamamatsu). End plates were quantified only if the captured imaged accurately reflected the entire threedimensional structure of the synapse. Captured images were analyzed for presynaptic and postsynaptic areas and synaptic vesicle fluorescence (corrected for background) using IPLab software (version 4.0; BD Biosciences), as previously described (Chipman et al., 2010). All representative images are shown as collapsed $z$-stacks acquired using an LSM510 laser scanning confocal microscope (Zeiss Microimaging) and managed using Zen 2009 software (Zeiss Microimaging).

Synapses were characterized as parent terminals if they possessed a large-caliber innervating axon that was variegated in diameter, and showed homogenous synaptophysin (syp) or SV2 immunolabeling throughout the end-plate region (Schaefer et al., 2005). Synapses were characterized as reinnervated if they possessed a small-caliber innervating axon (which was often seen arising as a terminal or nodal sprout) and punctate synaptophysin or SV2 immunolabeling at the end-plate region (Schaefer et al., 2005). Axons were visualized either by colabeling with antibodies against neurofilament (NF) or by faint synaptophysin immunolabeling. Terminal bridges were measured if both the parent terminal and the reinnervated terminal could be unambiguously identified based on synaptophysin and neurofilament immunolabeling.

FM4-64 loading and imaging ex vivo preparations. FM4-64FX ( $5 \mu \mathrm{M}$; Invitrogen) was added to the recording chamber containing dissected soleus muscles $5 \mathrm{~min}$ before stimulating the soleus nerve at $50 \mathrm{~Hz}$ for 5 min (a $1 \mathrm{~s}$ train of pulses every $2 \mathrm{~s}$ ). Following stimulation, muscles were left for $10 \mathrm{~min}$ to allow for residual endocytosis (Gaffield and Betz, 2006). Loaded muscles were washed for $40 \mathrm{~min}$ with low $\mathrm{Ca}^{2+}$ Tyrode's solution containing the following to prevent vesicle cycling during the wash period (in mM): $\mathrm{NaCl} 125, \mathrm{KCl} 5.37, \mathrm{NaHCO}_{3} 24, \mathrm{MgCl}_{2} 5, \mathrm{CaCl}_{2} 0.6$, and dextrose 27.75 (Maeno-Hikichi et al., 2011). They were then prepared for immunofluorescence labeling, as described above. The $z$-stacks of identified NMJs were captured with an LSM510 laser scanning confocal microscope (Zeiss Microimaging). Synaptophysin fluorescence was excited with a $488 \mathrm{~nm}$ excitation laser, and emission was captured with a $500-530 \mathrm{~nm}$ bandpass filter. $\alpha$-BTX fluorescence was excited with a 543 $\mathrm{nm}$ laser excitation, and emission was captured with a 565-615 nm bandpass filter. FM4-64FX was excited with a $488 \mathrm{~nm}$ laser, and emission was captured with a 685 longpass filter. Fluorescence intensity measurements were quantified and corrected for background on collapsed $z$-stacks using Zen 2009 software (Zeiss Microimaging).

Intraperitoneal treatment of mice. Nifedipine was dissolved in DMSO and added to sterile saline solution for a final concentration of $5 \mathrm{mg} / \mathrm{ml}$. Mice were injected daily ( $50 \mathrm{mg} / \mathrm{kg}$, i.p.) in the afternoon for $7 \mathrm{~d}$, beginning $7 \mathrm{~d}$ post-partial denervation (pPD) until the day before the acute experiment. An equal volume of DMSO diluted in sterile saline solution was used as a vehicle control (stock nifedipine/DMSO solutions were diluted in a saline solution and used at a final concentration of $1 \%$ DMSO).

Quantification of motor neuron number and motor unit size. Spinal cords from CTB-injected mice were sectioned longitudinally at $40 \mu \mathrm{m}$, as previously described (Franz et al., 2005). Raw cell counts were corrected by the Abercrombie method (Abercrombie, 1946). The mean motor unit size was determined by relating the number of innervating motor neurons to the mean number of muscle fibers composing the soleus muscle ( $\sim 800$; Chipman et al., 2010), and the degree of innervation following partial denervation as determined by syp ${ }^{+} / \mathrm{NF}^{+}$immunofluorescence.

Drug treatments. For all ex vivo experiments including the use of drug treatments, drug solvents (vehicle) were used as controls. Nifedipine (Sigma) was used to block L-VDCCs and was dissolved in 99\% EtOH. EtOH concentrations never exceeded $0.1 \%$. A $50 \mu \mathrm{M}$ concentration of nifedipine was used in acute experiments, while a $5 \mu \mathrm{M}$ concentration was used for chronic experiments. ATX was used to block P/Q-type VDCCs, and was dissolved in distilled water and used at a final $100 \mathrm{nM}$ concentration.

Statistical analysis. One-way ANOVAs were performed to examine the differences between groups over time. Holm-Sidak or Dunn's pairwise multiple-comparisons test were then used to determine where significant differences occurred if the $F$ value exceeded $F$ critical. Two tailedStudent's $t$ tests were used when comparing two groups if normality was achieved. If normality was not achieved, the Mann-Whitney test or ANOVA on ranks was used to compare between groups. Statistical significance was considered to be achieved at $p<0.05$.

\section{Results}

\section{Functionally effective synaptic sprouting requires presynaptic NCAM}

To assess the role of presynaptic NCAMs during compensatory synaptic sprouting, we bred mice expressing cre recombinase under the control of the motor neuron-specific $\mathrm{Hb} 9$ promoter (Hb9 ${ }^{\text {cre }}$ mice; Yang et al., 2001) with mice expressing a floxed NCAM gene (Bukalo et al., 2004). The resulting offspring $\left(H b 9^{c r e} N C A M^{f l x}\right.$ mice) have motor neurons lacking NCAM (Franz et al., 2008; Chipman et al., 2010). Wild-type $\left(N C A M^{+/+}\right.$) and $H b 9^{c r e} N C A M^{f l x}$ soleus muscles were partially denervated via L5 spinal root transection (Fig. $1 A$, right diagram), and the regenerative response was evaluated at a variety of time points post partial denervation ( $\mathrm{pPD}$ ).

L5 spinal root transection of adult (3- to 5-month-old) mice removed $\sim 75 \%$ of the innervation to the soleus muscle in both genotypes (Fig. 1B; Brown and Ironton, 1978; Rochel and Robbins, 1988; Tam et al., 2002). We did not observe any difference in the complement of L4 and L5 innervation to soleus muscles (Fig. $1 B)$ or in the pattern of intramuscular nerve branching in $H b 9^{c r e} N C A M^{f l x}$ mice (data not shown). These observations indicate that gross neuromuscular anatomy and developmental neuromuscular innervation are largely independent of NCAM in mice (Moscoso et al., 1998).

The functional consequence of MU loss and compensatory sprouting capacity was assessed by first measuring peak tetanic forces generated from partially denervated soleus muscles in response to a $1 \mathrm{~s}$ train of stimuli delivered to motor axons at $50 \mathrm{~Hz}$ (Fig. 1C,D). This stimulation frequency produced maximal muscle tension (data not shown) and is typical of endogenous soleus muscle activation (Gorassini et al., 2000). Contralateral (unoperated) soleus muscles isolated from $\mathrm{NCAM}^{+/+}$and $H b 9^{\text {cre }} N C A M^{f l x}$ mice generated comparable forces (Fig. 1C,D; $p=0.136, t$ test, $N C A M^{+/+}$vs $H b 9^{\text {cre }} N C A M^{f l x}$; see also Chipman et al., 2010). Consistent with the degree of denervation, the soleus tetanic forces decreased by $75-80 \%$ in both genotypes $7 \mathrm{~d}$ pPD (Fig. $1 C, D ; p=0.94 t$ test, $N C A M^{+/+}$vs $H b 9^{\text {cre }} N C A M^{f l x}$ ). However, while the contractile force of $\mathrm{NCAM}^{+/+}$soleus muscles increased to near normal values another $7 \mathrm{~d}$ later (Fig. $1 C, D$ ), the contractile forces of the partially denervated $\mathrm{Hb}^{\text {cre }} \mathrm{NCAM}{ }^{f l x}$ soleus muscles did not change (Fig. $1 C, D ; p<0.05$, one-way ANOVA) and remained significantly weaker than wild-type muscles (Fig. $1 D ; p<0.05$, Student's $t$ test, $N C A M^{+/+}$vs $\left.H b 9^{\text {cre }} N C A M^{f l x}\right)$. Thus, the functional recovery of motor output following partial denervation requires NCAM expression in motor neurons.

To examine end-plate innervation in partially denervated $N C A M^{+/+}$and $H b 9^{c r e} N C A M^{f l x}$ soleus muscles, we scored the number of rhodamine-conjugated $\alpha$-BTX-positive postsynaptic end plates (shown as a percentage) that were contacted by a synaptophysin-positive motor terminal. Consistent with our back-labeling and force measurements, the number of innervated end plates was significantly reduced in both genotypes at $7 \mathrm{~d}$ pPD (Fig. 1E). The degree of innervated end plates in partially denervated $\mathrm{NCAM}^{+/+}$muscles increased significantly by $14 \mathrm{~d}$ pPD (i.e., 80-85\%) and remained at this level for the next $16 \mathrm{~d}$ (Fig. $1 E ; p>0.05$, one-way ANOVA). End-plate innervation did increase slightly in $H b 9^{\text {cre }} N C A M^{f l x}$ soleus muscles over time (Fig. $1 F$ ). However, the degree of innervation was significantly 
A
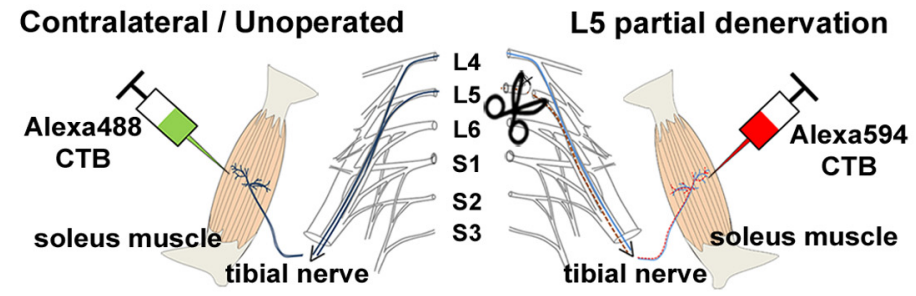
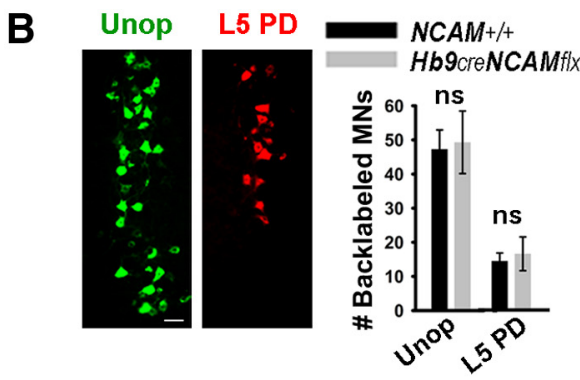

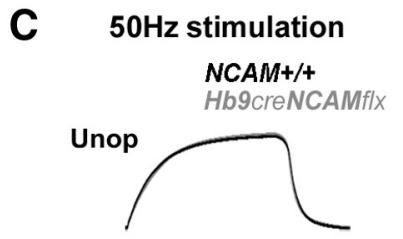

Day 7

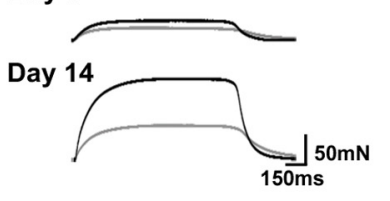

D

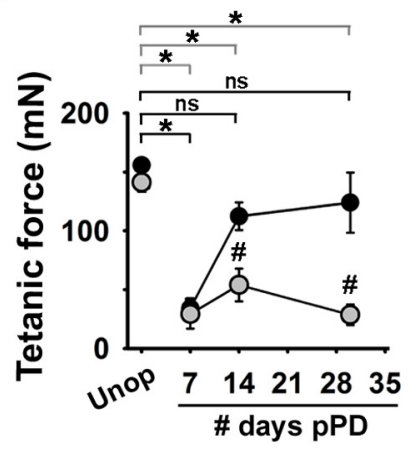

E

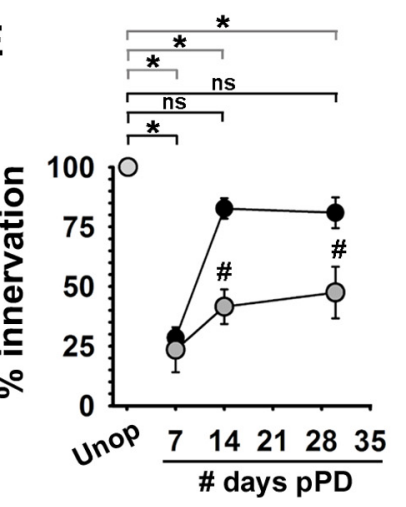

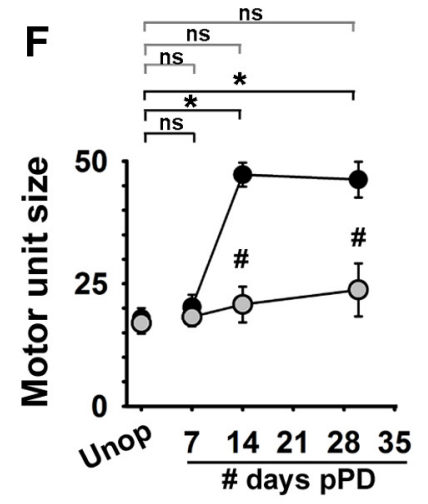

Figure 1. Presynaptic NCAM is required for functional motor unit expansion. $\boldsymbol{A}$, Schematic representation of $L 5$ partial denervation surgery and motor neuron back-labeling. $\boldsymbol{B}$, Representative images and the mean number ( \pm SEM) of $\mathrm{CTB}^{+}$back-labeled motor neurons in longitudinal sections of spinal cord $3 \mathrm{~d}$ following unilateral L5 partial denervation. Contralateral (unop) and ipsilateral (L5 PD) motor neurons and counts are shown. $n=5$ for each genotype. Student's $t$ test: $p=0.759$ and $p=0.697$ for unoperated and partially denervated spinal cords, respectively. Scale bar, 40 $\mu \mathrm{m}$. C, Representative tetanic ( $50 \mathrm{~Hz}$ for $1 \mathrm{~s}$ ) force profiles generated by partially denervated and contralateral NCAM ${ }^{+/+}$(black) and $H b 9^{\text {cre }} N C A M^{f l x}$ (gray) soleus muscles 7 and $14 \mathrm{~d} \mathrm{pPD.} \mathrm{D,} \mathrm{Soleus}$ tetanic forces ( \pm SEM) generated by partially denervated and contralateral (unop) soleus muscles. $\boldsymbol{E}$, Mean ( \pm SEM) percentage muscle innervation 7,14 , and $30 \mathrm{~d}$ pPD. $\boldsymbol{F}$, Mean ( \pm SEM) motor unit sizes as determined by anatomical assessments of muscle innervation in relation to the number of remaining motor neurons. ${ }^{*} p<0.05$, one-way ANOVA and Holm-Sidak multiple-comparisons test (black, NCAM ${ }^{+/+}$; gray, Hb9 $\left.9^{\text {cre }} N C A M^{f l x}\right)$; \#p $<0.05$, Student's $t$ test, $N C A M^{+/+}$vs $H b 9^{\text {cre }} N C A M^{f l x}$. ns, Not significantly different. NCAM ${ }^{+/+}:$unop, $n=6 ; 7 \mathrm{~d}, n=5 ; 14 \mathrm{~d}, n=6 ; 30 \mathrm{~d}, n=5$. $H b 9^{c r e} N C A M^{f l x}$ : unop, $n=6 ; 7 \mathrm{~d}, n=4 ; 14 \mathrm{~d}, n=6 ; 30 \mathrm{~d}, n=5$.

less than partially denervated $\mathrm{NCAM}^{+/+}$muscles at 7 and $14 \mathrm{~d}$ pPD (Fig. $1 E ; p<0.05, t$ test, $N C A M^{+/+}$vs $H b 9^{\text {cre }} N C A M^{f l x}$ ). When we estimated MU size by comparing the innervation of soleus muscles to the number of back-labeled motor neurons following partial denervation, we found that recovery of force in $N C A M^{+/+}$mice was due to an expansion in MU size (Fig. $1 F ; p<$ 0.001 , one-way ANOVA). MU size did not increase in partially denervated $H b 9^{c r e} N C A M^{f l x}$ mice (Fig. $1 F$ ). Together, these results indicate that sprouting is compromised in partially denervated muscles when motor neurons lack NCAM.

\section{Presynaptic NCAM mediates regenerative} presynaptic differentiation

While assessing end-plate innervations, we noticed that there was a tremendous range in the degree of overlay between presynaptic and postsynaptic structures at NMJs in partially denervated muscles. To examine these differences in more detail, we immunolabeled NMJs for presynaptic structures such as SVs (using syp) and NFs, as well as postsynaptic AChRs (i.e., $\alpha$-BTX; Fig. 2A). Figure $2 A$ shows typical examples of soleus muscles in $N C A M^{+/+}$ and $H b 9^{\text {cre }} N C A M^{f l x}$ mice $14 \mathrm{~d}$ pPD, where several AChR-rich end plates were completely overlaid with synaptophysin immunolabeling (Fig. $2 A$, arrow and arrowheads), while others were not (Fig. $2 A$, open arrowheads). In addition, several $\alpha$-BTX ${ }^{+}$end plates in partially denervated $H b 9^{\text {cre }} N C A M^{f l x}$ mice were completely denervated (Fig. $2 A$, asterisks). To quantify these observations, we measured the amount of overlap between SVs (using syp immunofluorescence) and AChRs (using rhodamineconjugated $\alpha$-BTX) at each end plate, and presented these measurements as the percentage occupation of the synapse (Fig.
$2 B-D)$. Completely denervated end plates were defined as those with $0 \%$ occupation. As shown above, $\sim 16 \%$ and $55 \%$ of the end plates remained completely denervated in $\mathrm{NCAM}^{+/+}$and $H b 9^{c r e} N C A M^{f l x}$ muscles $14 \mathrm{~d}$ pPD, respectively [Fig. $2 B$ (note different $y$-axis values)]. As expected from our observations, the range in occupation was significantly higher for both genotypes at $14 \mathrm{~d}$ pPD compared with unoperated control muscles (Fig. $2 B$ ). However, while presynaptic occupation increased between 14 and $30 \mathrm{~d}$ in $\mathrm{NCAM}^{+/+}$muscles (indicated as a shift to higher values in the frequency histograms; Fig. $2 B$; $p<0.001$, MannWhitney rank sum test), it progressively decreased at $H b 9^{c r e} N C A M^{f l x}$ end plates over the same time period (Fig. $2 B ; p=$ 0.041, Mann-Whitney rank sum test). These differences are further illustrated when the percentage occupation of only the innervated end plates is plotted as a cumulative frequency histogram (Fig. 2C). Figure $2 \mathrm{C}$ also shows a shift to the right over time in partially denervated $\mathrm{NCAM}^{+/+}$muscles, while it shifts to the left in partially denervated $H b 9^{\text {cre }} N C A M^{f l x}$ muscles. Finally, the mean percentage occupation was significantly less than that of $N_{C A M}{ }^{+/+}$muscles at both time points in partially denervated $H b 9^{\text {cre }} N C A M^{f l x}$ muscles (Fig. 2D).

The reduced overlap between SVs and AChRs at reinnervated NMJs in partially denervated $H b 9^{\text {cre }} N C A M^{f l x}$ mice could be due to reduced end-plate reinnervation of individual end plates by axonal sprouts or by impaired SV mobilization toward reinnervated end plates. To distinguish between these two possibilities, we quantified the area occupied by SVs (Fig. $2 F$ ), the size of the end plate (Fig. $2 G$ ), and the overall lengths of the intraterminal axons at reinnervated NMJs (Fig. $2 \mathrm{H}$ ), 14 and $30 \mathrm{~d}$ pPD. As shown in the representative image (Fig. 2E), SVs occupied 

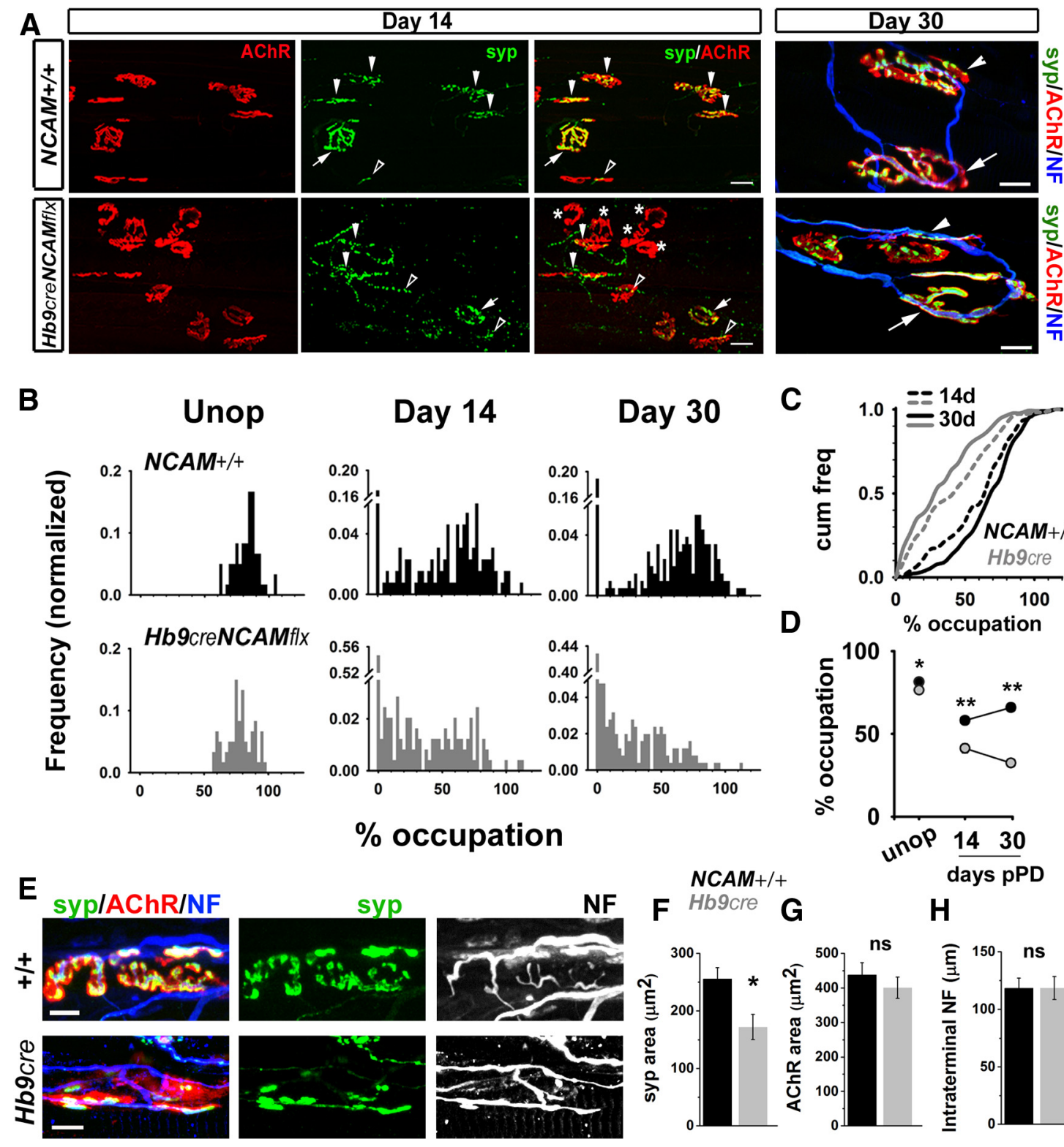

$N C A M+/+$ F Hb9cre G
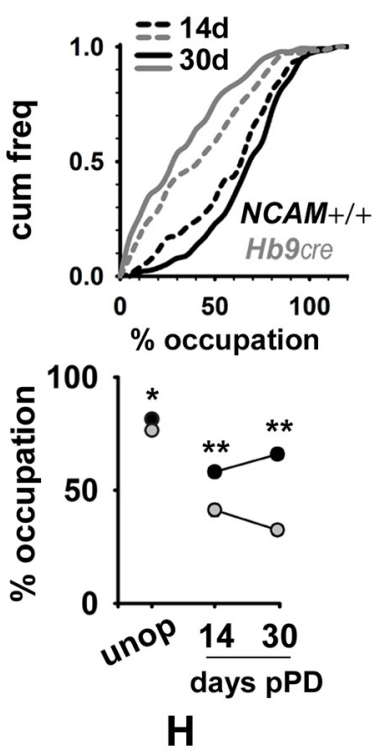

Figure 2. Reduced reinnervation in partially denervated $H b g^{\text {cre }} N C A M^{f l x}$ muscles. $\boldsymbol{A}$, Representative images of NMJs from partially denervated muscles labeled with $\alpha$-BTX (for AChRs), and antibodies against syp and NF to identify SVs and axons respectively. Scale bars: left, $20 \mu \mathrm{m}$; right, $10 \mu \mathrm{m}$. Arrows identify parent end plates; white arrowheads identify reinnervated end plates; black arrowheads identify contacted end plates; asterisks identify denervated NMJs. $\boldsymbol{B}$, Histograms showing the degree (percentage) of presynaptic occupation of postsynaptic end plates. $\boldsymbol{C}$, Cumulative frequency plot of data displayed in $\boldsymbol{B}$ demonstrating the change in end-plate occupation 14 and $30 \mathrm{~d}$ pPD. D, Same data as displayed in $\boldsymbol{C}$ depicted as mean \pm SEM. ${ }^{*} p=0.007$, ${ }^{* *} p<$ 0.001 , Mann-Whitney rank sum test, $N C A M^{+/+}$vs $H 69^{\text {cre }}$ NCAM $^{\text {fx }}$. NCAM ${ }^{+/+}$: unop, $n=60$ NMJs from three muscles; $14 \mathrm{~d}, n=108$ NMJs from three muscles; $30 \mathrm{~d}, n=167$ NMJs from three

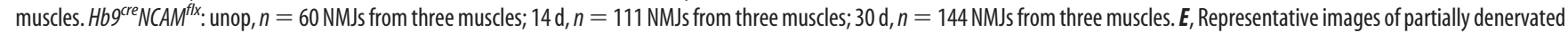
NCAM and $H b g^{\text {cre }} N C A M^{f x}$ soleus muscles immunolabeled for syp and NF, and counterstained with rhodamine-conjugated $\alpha$-BTX (for AChRs). $\boldsymbol{F}-\boldsymbol{H}$, Mean ( \pm SEM) syp (F) and AChR areas (G), and total length of intraterminal NF + axons $(\boldsymbol{H})$ measured in triple-labeled synapses at 14 and $30 \mathrm{dpPD} .{ }^{*} p=0.0146$, Mann-Whitney rank sum test. NCAM ${ }^{+/+}: n=22 \mathrm{NMJs}$ from seven muscles. $H b g^{\text {cre }}$ NCAM $^{f f x}: n=27$ NMJs from eight muscles.

a significantly smaller area at reinnervated end plates in $H b 9^{c r e} N C A M^{f l x}$ mice compared with $\mathrm{NCAM}^{+/+}$mice (Fig. $2 F$; $p=0.015$, Mann-Whitney rank sum test). In contrast, the size of the end plates (Fig. 2G; $p=0.648$, Mann-Whitney rank sum test) and the total length of the intraterminal axons were not significantly different between genotypes (Fig. $2 H ; p=0.856$, Mann-Whitney rank sum test). These results indicate that the attenuated distribution of SVs at reinnervated end plates in partially denervated muscles in $H b 9^{c r e} N C A M^{f l x}$ mice compared with $\mathrm{NCAM}^{+/+}$mice is not due to reinnervation. Rather, it appears to reflect improper SV mobilization along axonal sprouts; a phe- nomenon that was also observed at end plates in neonatal $\mathrm{NCAM}^{-/-}$mice (Rafuse et al., 2000).

In addition to a tremendous range in the degree of overlay between synaptophysin-positive vesicles and AChRs in partially denervated muscles, we also observed extensive synaptophysinpositive immunolabeling at regions between $\alpha$-BTX ${ }^{+}$staining (Fig. 2A, syp). To quantify these observations, we traced intensity line plots through parent terminals, along terminal bridges, and through reinnervated terminals, and measured the fluorescence intensity of synaptophysin at each of these regions (Fig. 3A-D; see Materials and Methods for criteria used to classify parent 

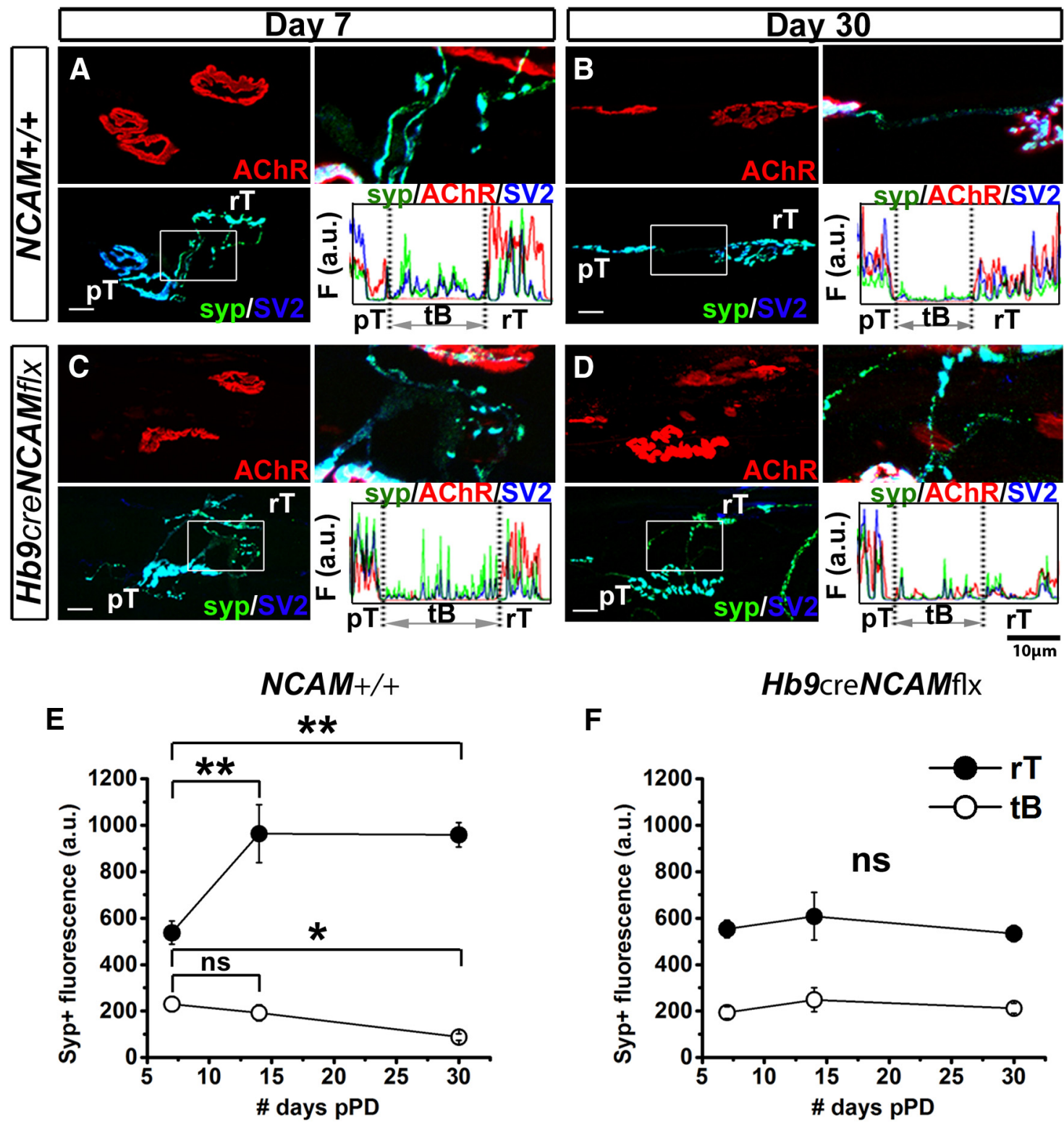

Figure 3. Synaptic vesicles fail to localize to newly sprouted synapses in partially denervated $H b g^{\text {cre }} N C A M^{f x}$ muscles. $A-D$, Representative images of NMJs in $N C A M^{+/+}(\boldsymbol{A}, \boldsymbol{B})$ and $H b g^{c r e} N C A M^{f x}$ muscles $(\boldsymbol{C}, \boldsymbol{D})$ at $7 \mathrm{~d}(\boldsymbol{A}, \boldsymbol{C})$ and $30 \mathrm{~d}(\boldsymbol{B}, \boldsymbol{D})$ pPD. NMJs were labeled with $\alpha$-BTX, and antibodies against syp and SV2. Magnified boxed regions are shown in the top right panel. Representative fluorescence intensity line plots (bottom right) were generated from images in $A-D$ by drawing a line through the parent terminal (pT), along the terminal bridge (tB), and through the reinnervated terminal (rT). Scale bars, $10 \mu \mathrm{m}$. $E$, Mean ( \pm SEM) fluorescence intensities of syp ${ }^{+}$puncta at synaptic regions of reinnervated terminals ( $\mathrm{rTs}$ ) and extrasynaptic regions of tBs in partially denervated $\mathrm{NCAM}^{+/+}$muscles. A reinnervated terminal and its associated bridge were always measured in pairs. Day 7, $n=31$ synapses from three muscles; Day $14, n=49$ synapses from three muscles; Day $30 n=62$ synapses from three muscles. $\boldsymbol{F}$, Mean ( \pm SEM) fluorescence intensities of syp ${ }^{+}$puncta at synaptic regions of rTs and extrasynaptic regions of tBs in partially denervated $H b b^{c r e} N C A M^{f x}$ muscles. Day $7, n=32$ synapse from three muscles; Day $14, n=44$ synapse from three muscles; Day $30, n=67$ synapse from three muscles. ${ }^{*} p<0.05$, ${ }^{* *} p<0.001$ one-way ANOVA followed by Dunn's pairwise multiple-comparisons test.

and reinnervated terminals). The fluorescence intensity of synaptophysin-positive puncta in sprouts was used as an optical measure of vesicle abundance at synaptic and extrasynaptic regions because it is the most highly enriched SV protein (Takamori et al., 2006). This analysis revealed several changes in SV distribution in partially denervated $\mathrm{NCAM}^{+/+}$and $H b 9^{c r e} N C A M^{f l x}$ muscles between 7 and $30 \mathrm{~d}$. First, the abundance of SVs at reinnervated $\mathrm{NCAM}^{+/+}$terminals increased between 7 and $14 \mathrm{~d} \mathrm{pPD}$, where it reached a plateau (Fig. 3E, closed circles; $p<0.001$, one-way ANOVA), while the abundance of SVs in the terminal bridges decreased significantly between 7 and $30 \mathrm{~d}$ pPD (Fig. 3E, open circles; $p<0.001$, one-way ANOVA). In contrast, the abundance of SVs at reinnervated terminals in
$H b 9^{c r e} N C A M^{f l x}$ muscles did not increase over time (Fig. 3F, closed circles; $p=0.108$, one-way ANOVA), nor was there a change in the abundance of SVs in the terminal bridges (Fig. 3F, open circles; $p=0.971$, one-way ANOVA). These results suggest that SV mobilization is abnormal in axonal sprouts lacking NCAMs in partially denervated muscles.

Because SV mobilization was impaired, we next wanted to determine whether NCAM is associated with SVs in axonal sprouts pPD. To address this issue, we used an ex vivo nerve/ muscle preparation to electrically stimulate $\mathrm{NCAM}^{+/+}$soleus muscles, which were partially denervated $14 \mathrm{~d}$ previously, at 50 $\mathrm{Hz}$ for $5 \mathrm{~min}$. FM4-64 was added to the preparation to visualize actively cycling SVs (see Materials and Methods for details). The 
A
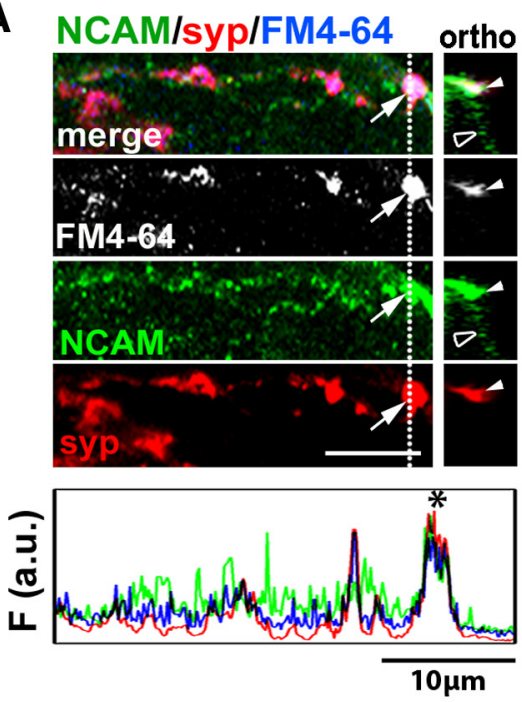

B NCAM+/+ NCAM/AChR/syp
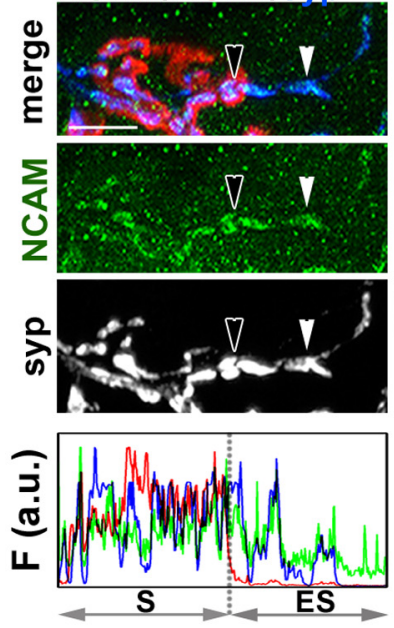

D
Hb9creNCAMflx
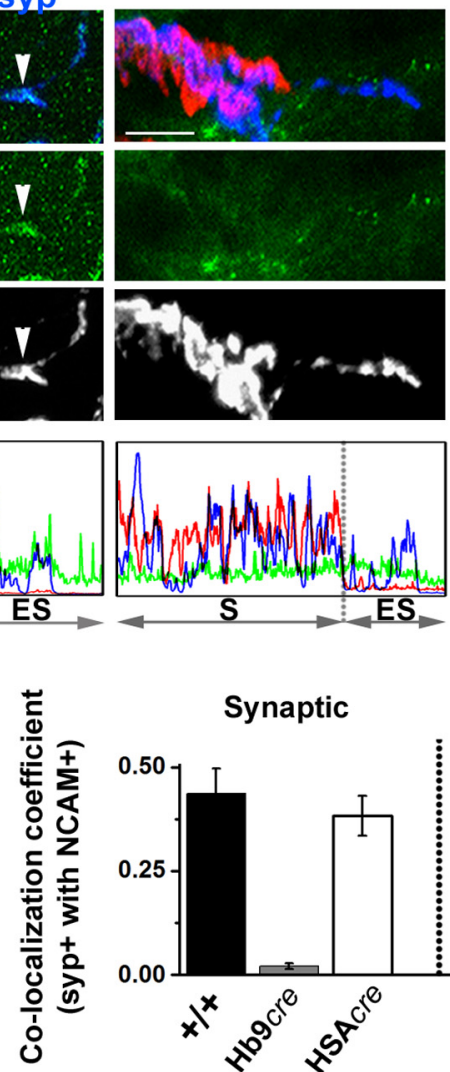

HSAcreNCAMflx
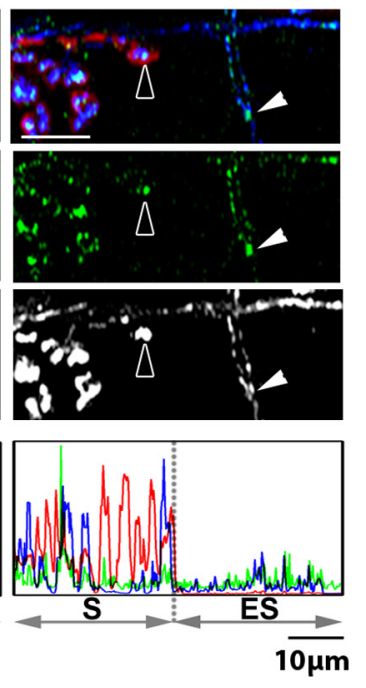

C

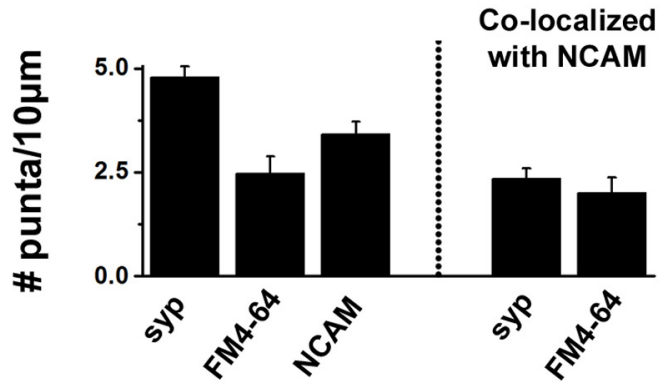

Synaptic

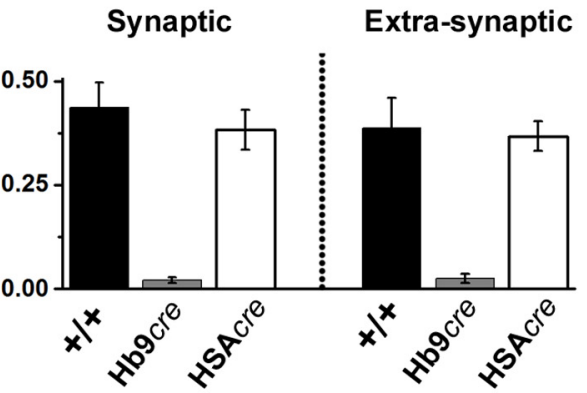

Figure 4. NCAM colocalizes with actively cycling SVs in terminal sprouts $14 \mathrm{~d}$ pPD. $\boldsymbol{A}$, NCAM (green) partially colocalizes with FM4-64FX signal (white or blue in merged image) and syp immunofluorescence (red) at the tips of growing sprouts (arrow). ortho, Orthogonal view of the region identified by the dotted line. White arrowheads indicate presynaptic labeling. Open arrowheads indicate postsynaptic NCAM labeling along muscle fibers. Scale bar, $5 \mu \mathrm{m}$. Bottom, Fluorescence line plots through the end-plate region and into the axonal sprout. Green, NCAM; red, syp; blue, FM4-64. B, $\alpha$-BTX ${ }^{+}$NMJs in partially denervated NCAM ${ }^{+/+}, H b 9^{c r e} N C A M^{f l x}$, and $H S A^{c r e} N C A M^{f l x}$ soleus muscles immunolabeled with antibodies against NCAM and syp. HSA ${ }^{\text {cre }} N C A M^{f l x}$ mice are muscle-specific NCAM-null mice. Open and white arrowheads indicate colocalization of syp and NCAM immunofluorescence at synaptic and extrasynaptic sites, respectively. Bottom, Fluorescence line plots through the end plate [i.e., synaptic region (S)] and into the extrasynaptic (ES) axonal sprout. Green, NCAM; red, $\alpha$-BTX; blue, syp. C, Mean ( \pm SEM) number of extrasynaptic syp, FM4-64, and NCAM puncta/10 $\mu \mathrm{m}$ section in 10-14 d partially denervated NCAM ${ }^{+/+}$muscles. Right, Mean ( \pm SEM) of syp and FM4-64 puncta colocalized with NCAM in extrasynaptic neurites in NCAM ${ }^{+/+}$mice. D, Mean ( \pm SEM) colocalization coefficient of syp ${ }^{+}$to NCAM ${ }^{+}$fluorescence signals in synaptic (left) and extrasynaptic (right) regions of 10 - to $14-d$-old partially denervated muscles.

muscles were then processed for NCAM and synaptophysin immunohistochemistry. FM4-64, NCAM, and synaptophysin immunolabeling were later visualized using confocal microscopy. Figure $4 A$ shows an example of FM4 $-64^{+}$SVs expressing both NCAM and synaptophysin [Fig. 4A, arrow (arrowhead in the orthogonal view)]. Fluorescence intensity line plots through the image show an example where NCAM is closely associated with cycling (i.e., FM $4-64^{+}$) SVs (Fig. $4 A$, asterisks). To quantify this observation, we counted the number of puncta per $10 \mu \mathrm{m}$ of extrasynaptic sprouts at 10-14 d pPD that expressed FM4-64FX, NCAM, and synaptophysin (Fig. 4C). NCAM was identified in $65.9 \pm 10 \%$ of FM $4-64^{+}$puncta and in $51.6 \pm 5 \%$ of synaptophysin-positive puncta along this length (Fig. 4C). Figure $4 A$ also shows abundant NCAM immunofluorescence not associated with syp ${ }^{+}$vesicles. This immunofluorescence is likely due to NCAM expression in denervated muscles fibers. To examine this possibility more closely, we partially denervated the soleus in muscle-specific NCAM-null mice (i.e., $H S A^{c r e} N$ $C A M^{f l x}$ mice; see Materials and Methods for details) and compared these results with partially denervated muscles in $N C A M^{+/+}$and $H b 9^{c r e} N C A M^{f l x}$ mice. Figure $4 B$ shows NCAM expression by syp ${ }^{+}$SVs at synaptic (Fig. $4 B$, open arrowheads) and extrasynaptic regions (Fig. $4 B$, white arrowheads) in $N C A M^{+/+}$and $H S A^{\text {cre }} N C A M^{f l x}$ mice $14 \mathrm{~d}$ pPD. Fluorescence intensity line plots through the images (Fig. $4 B$ ) further illustrate that AChRs were absent at extrasynaptic sites and that NCAM was not colocalized with SVs in the Hb ${ }^{\text {cre }} N C A M^{f l x}$ mice. Quantification of colocalization coefficients at synaptic and extrasynaptic regions of NMJs in muscles $10-14 \mathrm{~d}$ pPD confirms that syp $^{+}$and $\mathrm{NCAM}^{+}$fluorescence puncta overlap in partially denervated $N C A M^{+/+}$and $H S A^{\text {cre }} N C A M^{f l x}$ muscles, but not $H b 9^{\text {cre }} N C A M^{f l x}$ muscles (Fig. $4 D$ ).

Together, these results indicate that the NCAM is expressed by a subset of cycling SVs in motor neurons. These results are consistent with previous studies showing that NCAM is associated with SVs at central synapses and at the NMJ. These include an in composition (Takamori et al., 2006) and Western blot analysis of highly purified SVs (Shetty et al., 2013), as well as NCAM immuno-electron microscopy at the NMJ (Covault and Sanes, 1986). Presynaptic NCAM is thus well positioned to influence the distribution of SVs in axonal sprouts following partial denervation. 


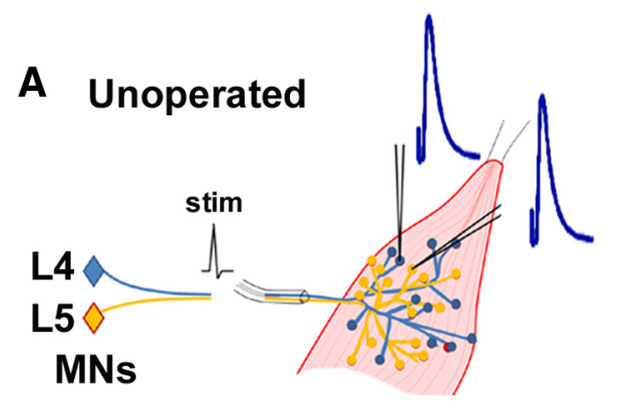

B
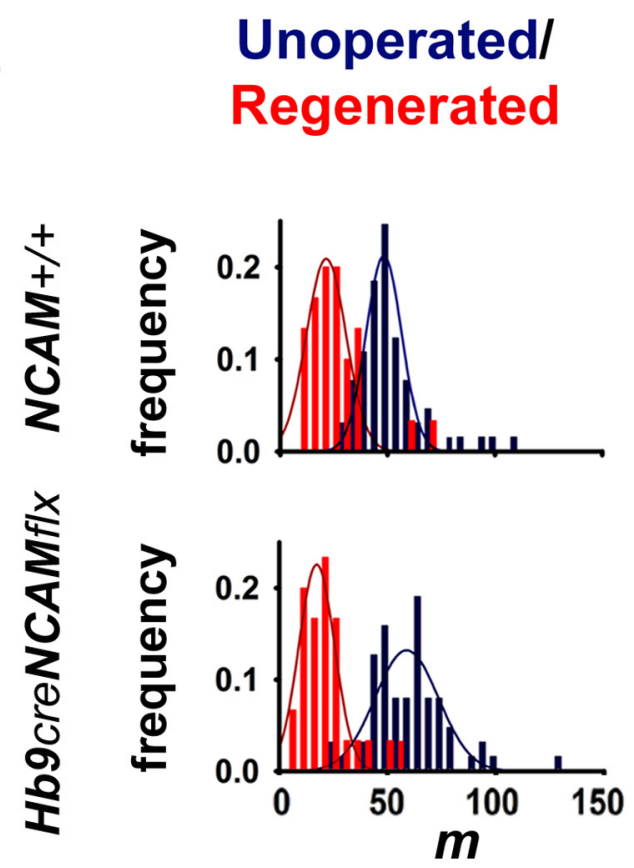

C

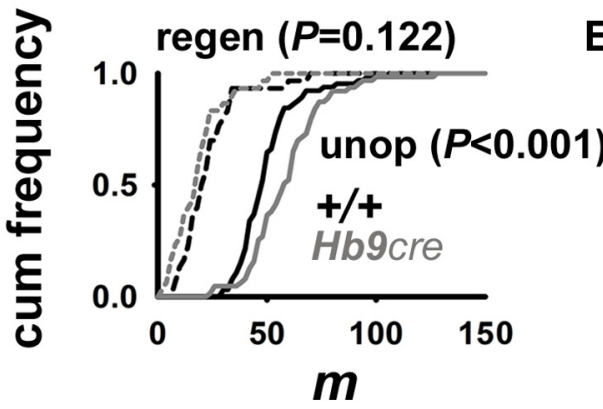

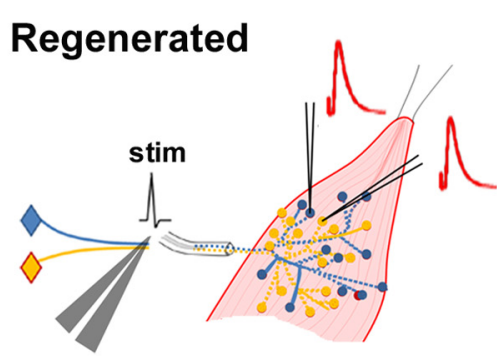
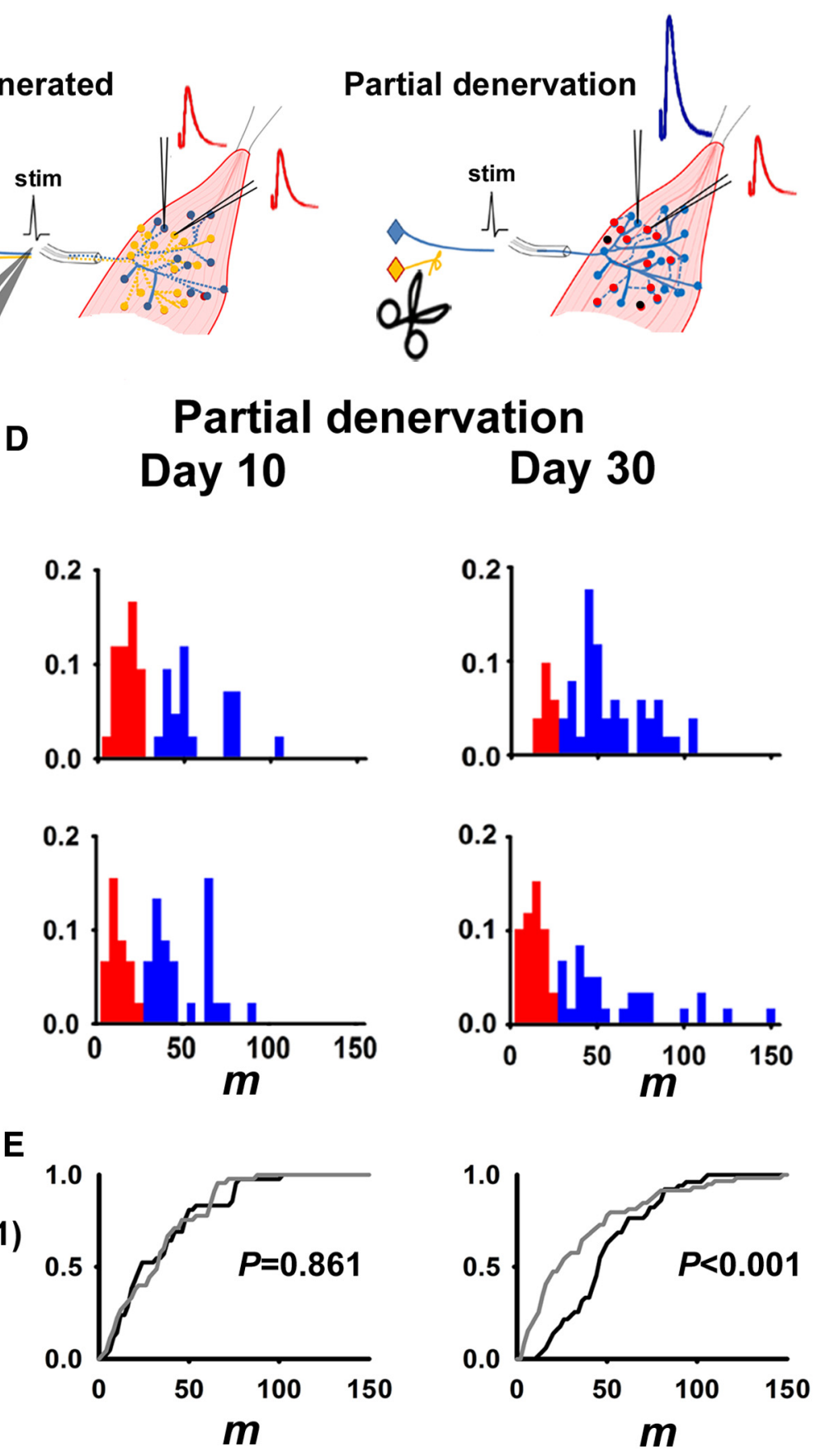

Figure 5. Newly reinnervated NMJs fail to functionally mature in partially denervated muscles in the absence of presynaptic NCAM. $A$, Diagram summarizing the functional diversity of end plates encountered during random sampling of unoperated, completely denervated (i.e., regenerated), and partially denervated muscles using sharp electrode intracellular recordings. Two populations of functional synapses were encountered; mature synapses (blue) and immature synapses (red). $\boldsymbol{B}, \boldsymbol{C}$, Frequency histograms $(\boldsymbol{B})$ and cumulative frequency plot $(\boldsymbol{C})$ showing the distribution of $m$ values recorded from mature NMJs in unoperated muscles and newly reinnervated $N C A M^{+/+}$and $H B g^{\text {cre }} N C A M^{f f x}$ NJMs $7 \mathrm{~d}$ after a complete nerve crush. $\boldsymbol{D}, \boldsymbol{E}$, Frequency histograms $(\boldsymbol{D})$ and cumulative frequency plots $(\boldsymbol{E})$ showing the distribution of $m$ values recorded from NMJs in NCAM ${ }^{+/+}$and $H B g^{\text {cre }} N C A M^{f x}$ muscles 10 and $30 \mathrm{~d} p$ PD. The $p$ values shown are the result of Mann-Whitney rank sum tests.

Presynaptic NCAM is required for functional maturation of motor terminals

We next used sharp electrode intracellular recordings to assess how a loss of presynaptic NCAM affects motor end-plate maturation in partially denervated muscles. Because we could not anatomically distinguish pre-existing parent terminals from newly reinnervated synapses in partially denervated muscles during the recordings, we chose to identify the two types using neurotransmission profiles (Fig. 5A). This approach is based on the assump- tion that quantal content is significantly smaller at newly reinnervated end plates compared with mature terminals (Rochel and Robbins, 1988; Chipman et al., 2010). To test this assumption, we completely denervated the soleus by crushing the tibial nerve in $N C A M^{+/+}$and $H b 9^{c r e} N C A M^{f l x}$ mice, and measured quantal contents at motor terminals $7 \mathrm{~d}$ later (Fig. $5 A$, regenerated) or at motor terminals in contralateral, unoperated muscles (Fig. $5 A$, unoperated). Figure $5 B$ shows that quantal content is significantly lower at reinnervated end plates in $\mathrm{NCAM}^{+/+}$and 


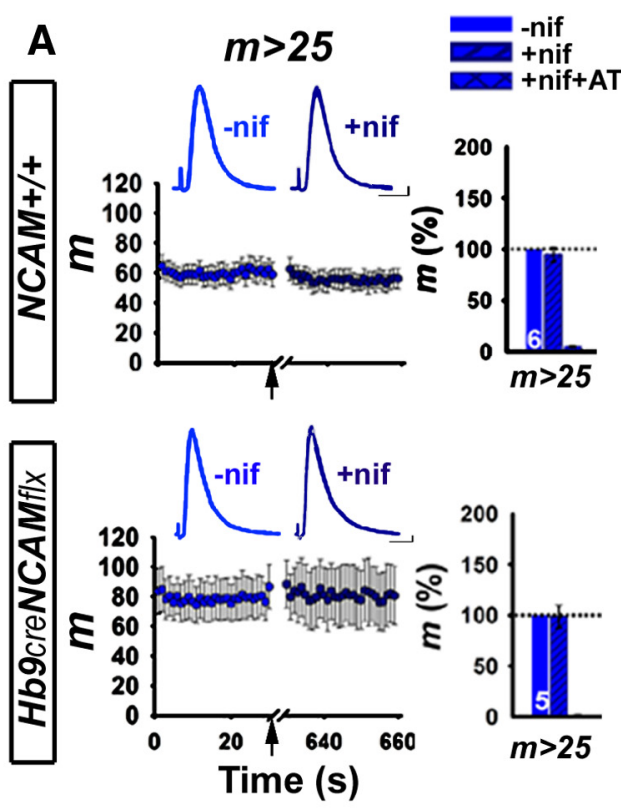

D

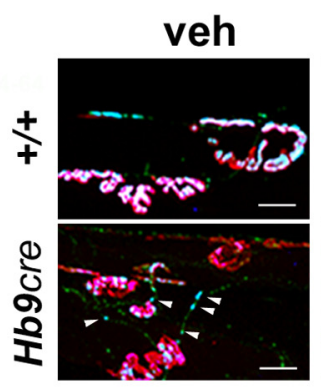

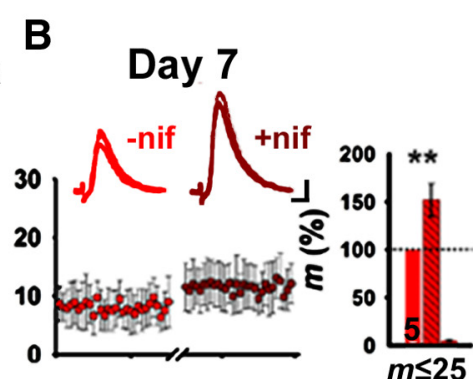

C Day 14
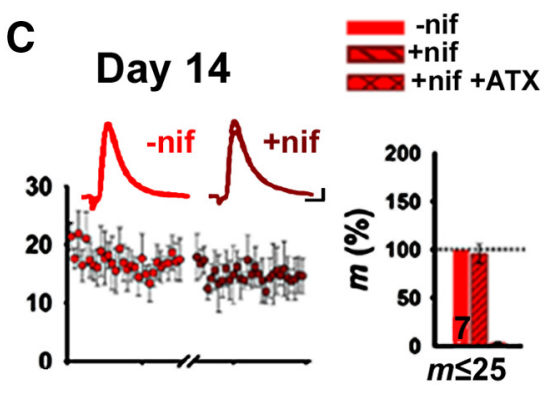
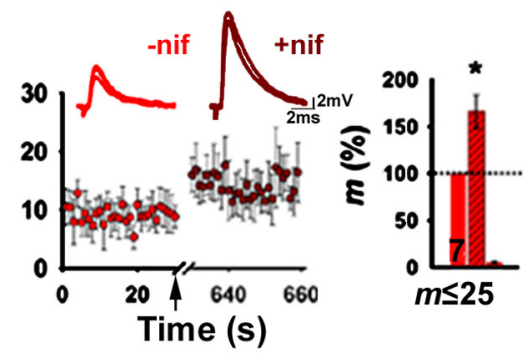

Figure 6. Nifedipine potentiates neurotransmission at newly sprouted NMJs. $\boldsymbol{A}-\boldsymbol{C}$, Representative intracellular recordings of EPPs and mean ( \pm SEM) $m$ values recorded from unoperated, mature $(m>25 ; \boldsymbol{A})$, and immature $(m \leq 25)$ synapses $(\boldsymbol{B}, \boldsymbol{C})$ at $7 \mathrm{~d}(\boldsymbol{B})$ and $14 \mathrm{~d}(\boldsymbol{C})$ pPD. Recordings were made before ( - nif) and after ( + nif) application of $50 \mu m$ nifedipine. Axons were stimulated at $1 \mathrm{~Hz}$ to elicit EPPs. Inserts show mean ( \pm SEM) percentage change in $m$ values following the application of nifedipine. The $100 \mathrm{~nm}$ ATX was subsequently added to determine the contribution of $\mathrm{P} / \mathrm{Q}$-type VDCCs. The number of muscles assessed is indicated in the bars. ${ }^{*} p<0.05,{ }^{* *} p<0.01$, Student's $t$ test, - nif vs + nif. $D$, Representative images of NMJs in NCAM ${ }^{+/+}$and $H b 9^{\text {cre }} N C A M^{f l x}$ soleus $30 \mathrm{~d}$ pPD. NMJs were loaded with FM4 - 64 in the presence of vehicle (veh; EtOH) or nifedipine ( + nif; $50 \mu \mathrm{m}$ ) and colabeled with antibodies against syp and $\alpha$-BTX. Arrowheads identify cycling extrasynaptic vesicle puncta. Scale bars, $20 \mu \mathrm{m}$. $\boldsymbol{E}$, Mean ( \pm SEM) FM4 -64 fluorescence at synaptic and extrasynaptic puncta in the presence of veh or + nif. ${ }^{*} p<0.05$, Student's $t$ test, $N C A M^{+/+}$vs Hb9 ${ }^{c r e} N C A M^{f l x}$. \#p $<0.05$, Student's $t$ test, S vs ES. The numbers of synapses or sprouts assessed from at least three different muscles are indicated in the bars. $F$, Representative image of a syp ${ }^{+}$sprout extending from an Hb9 ${ }^{c r e} N C A M^{f l x}$ end plate (AChR) coimmunostained with antibodies against syp, L-VDCCs and $\alpha$-BTX. Images are single optical sections ( $0.45 \mu$ m thickness). The colocalization coefficients of the syp ${ }^{+}$signal with the $\mathrm{L}-\mathrm{VDCC}^{+}$signal at the synaptic region and extrasynaptic region were 0.056 and 0.191 , respectively. Orthogonal (ortho) views are shown to the right. Scale bar, $10 \mu \mathrm{m}$.

$H b 9^{\text {cre }}$ NCAM ${ }^{f l x}$ mice (red bars) compared with unoperated muscles (dark blue bars) $7 \mathrm{~d}$ after nerve crush (Fig. $5 B, C, m$ ). This clear difference next allowed us to electrophysiologically distinguish newly reinnervated end plates from mature synapses in partially denervated soleus muscles in $\mathrm{NCAM}^{+/+}$and Hb $9^{\text {cre }} N C A M^{f l x}$ mice.

As predicted, random recordings from end plates in partially denervated $\mathrm{NCAM}^{+/+}$and $H b 9^{\text {cre }} N C A M^{f l x}$ mice revealed two distinct populations of end plates based on quantal content. The first population had quantal content values similar to those of unoperated controls, while the second population had reduced quantal transmission (Fig. 5D). Based on these observations, we defined immature synapses as those with $m \leq 25$ (red), while mature synapses had $m>25$ (blue). We chose to use the terms immature and mature, instead of reinnervated and parent, because reinnervated synapses most likely matured and acquired stronger transmission qualities, at least in $\mathrm{NCAM}^{+/+}$muscles, as the recovery process progressed. Denervated synapses not exhibiting evoked EPPs or spontaneous miniature EPPs (mEPPs) were also encountered. Although not directly quantified, the frequency of such synapses approximated the degree of innervation as determined by post hoc immunostaining for syp and $\alpha$-BTX (e.g., denervated fibers were encountered in $40 \%$ and $60 \%$, respectively, of the sampled myofibers in $\mathrm{NCAM}^{+/+}$and $H b 9^{c r e} N C A M^{f l x}$ animals $10 \mathrm{~d}$ pPD). The following functional assessments were thus restricted to responsive (i.e., innervated) synapses.

Consistent with our anatomical assessments of presynaptic occupancy, a population of immature synapses ( $m \leq 25$; red) emerged in both genotypes $10 \mathrm{~d}$ pPD (Fig. 5B). Overall, the distribution of synaptic strengths at this time point was comparable between genotypes (Fig. $5 D, E ; p=0.861, t$ test $N C A M^{+/+}$vs $H b 9^{\text {cre }} N C A M^{f l x} 10 \mathrm{~d}$ pPD). However, when assessed at later time points, the distribution of synaptic strengths clearly diverged 
(Fig. $5 D, E ; p<0.001, t$ test, $30 \mathrm{~d}$ pPD). While $\mathrm{NCAM}^{+/+}$values renormalized toward stronger quantal content values, those sampled from $H b 9^{c r e} N C A M^{f l x}$ muscles remained significantly skewed toward weaker values (Fig. $5 D$, E; $p<0.001$, MannWhitney rank sum test, $N C A M^{+/+}$vs $H b 9^{c r e} N C A M^{f x} 30 \mathrm{~d}$ pPD). These findings are consistent with the hypothesis that reinnervated terminals do not mature functionally when presynaptic NCAM is absent.

\section{Nifedipine potentiates neurotransmission at immature synapses}

Immature and regenerating motor terminals use an L-VDCC-dependent form of synaptic vesicle recycling (Katz et al., 1996; Sugiura and Ko, 1997; Siri and Uchitel, 1999; Polo-Parada et al., 2001; Hata et al., 2007), which persists in the absence of NCAM in vivo (Polo-Parada et al., 2001) and in vitro (Chipman et al., 2014). Moreover, blocking L-VDCCs at immature NMJs with nifedipine transiently potentiates neurotransmitter release (Sugiura and Ko, 1997; Siri and Uchitel, 1999). To determine whether this occurs at immature synapses in partially denervated muscles, we applied $50 \mu \mathrm{M}$ nifedipine while recording neurotransmission from mature $(m>25)$ and immature $(m \leq 25)$ synapses at various times PPD in both $N C A M^{+/+}$and $H b 9^{c r e} N C A M^{f l x}$ mice (Fig. 6A-C). Nifedipine had no effect at mature terminals in either genotype (Fig. $6 A$ ), while subsequent application of the P/Q-VDCC blocker ATX (100 nm) completely abolished evoked neurotransmission (Fig. 6A). In contrast, nifedipine significantly potentiated $m$ at immature synapses in both genotypes $7 \mathrm{~d}$ pPD. As expected, subsequent treatment with ATX completely abolished evoked neurotransmission at these synapses (Fig. 6B). Spontaneous mEPP amplitudes were not influenced by nifedipine or ATX (data not shown). Although the potentiating effect of nifedipine disappeared after $14 \mathrm{~d} \mathrm{pPD}$ in $\mathrm{NCAM}^{+/+}$mice, immature synapses in $H b 9^{c r e} N C A M^{f l x}$ mice continued to exhibit enhanced neurotransmission in the presence of nifedipine at the same time point (Fig. 6C).

To investigate anatomical correlates of blocking L-VDCCs in partially denervated ( $30 \mathrm{~d} \mathrm{pPD}) \mathrm{NCAM}^{+/+}$and $H b 9^{\text {cre }} N C A M^{f l x}$ muscles, we used an ex vivo nerve/muscle preparation to load SVs with FM4-64FX using a $50 \mathrm{~Hz}$ stimulation paradigm in the presence or absence of nifedipine. The muscles were then fixed and processed for synaptophysin immunohistochemistry and AChR labeling with rhodamine-conjugated $\alpha$-BTX (Fig. 6D). The distribution and intensity of FM4-64FX fluorescence was then quantified at synaptic (Fig. $6 E ; S$ ) and extrasynaptic sites near the end plates (Fig. $6 E$, ES). Figure $6 E$ shows the intensity of FM4-64 was higher at synaptic sites compared with extrasynaptic sites in $N C A M^{+/+}$muscles $30 \mathrm{pPD}$ when treated with vehicle or nifedipine. This indicates that significantly more
Days $\quad 0$

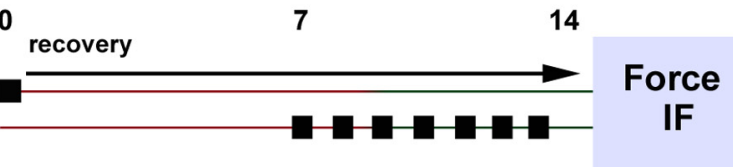

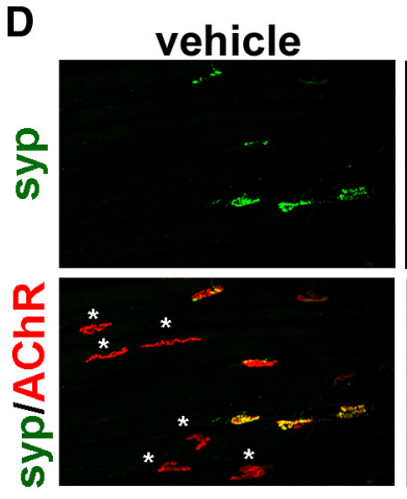
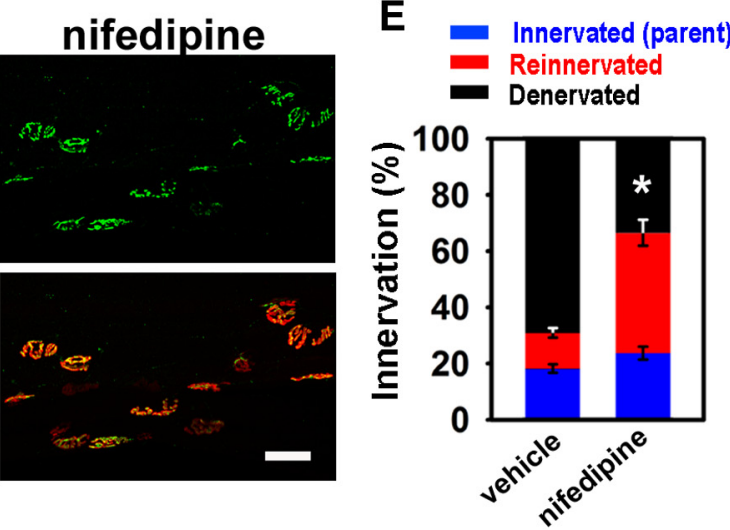

Hb9cre NCAM+/+ NCAMflx

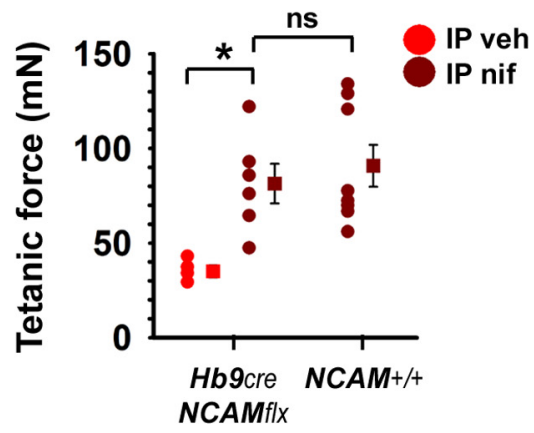

Figure 7. Chronic administration of nifedipine enhances soleus MU expansion in $H b g^{c r e} N C A M^{f l x}$ mice following partial denervation. $\boldsymbol{A}$, Protocol showing daily intraperitoneal administration of vehicle or nifedipine $(5 \mathrm{mg} / \mathrm{kg})$ starting $7 \mathrm{~d} \mathrm{pPD}$. B, Representative tetanic force profiles of partially denervated soleus muscles from $H_{b} g^{\text {cre }} N C A M^{f f x}$ mice intraperitoneally administered vehicle (IP veh) or nifedepine (IP nif). C, Individual (circles) and mean ( \pm SEM; boxes) tetanic forces generated from partially denervated nif). $\boldsymbol{D}$, Representative images of end plates in partially denervated soleus muscles in $H b 9^{\text {cre }} N C A M^{f t}$ mice that were administered vehicle or nifedipine. Asterisks indicate denervated end plates. Scale bar, $20 \mu \mathrm{m}$. E, Percentage of end plates innervated (mean \pm SEM) in partially denervated solues muscles in $H b 9^{\text {cre }} N C A M^{f x}$ mice administered vehicle (IP veh) or nifedipine (IP nif). ${ }^{*} p<0.05$ Student's $t$ test, IP veh vs IP nif. $H b g^{\text {cre }} N C A M^{f x}: I P$ veh, $n=4$ mice; IP nif, $n=6$ mice. $N C^{\prime} A M^{+/+}: I P$ nif, $n=8$ mice.

SVs were cycling at the synapse than at extrasynaptic sites during nerve stimulation and that this cycling was not altered when L-VDCCs were blocked. In contrast, the intensity of FM4-64FX fluorescence was the same at extrasynaptic and synaptic sites in partially denervated $H b 9^{c r e} N C A M^{f l x}$ muscles treated with vehicle (Fig. $6 E$ ). Interestingly, the application of nifedipine decreased FM4-64FX fluorescence intensity at extrasynaptic sites in $H b 9^{c r e} N C A M^{f l x}$ muscles such that it became significantly less than at the synapse (Fig. $6 D, E ; p<0.05$, Mann-Whitney rank sum test, $N C A M^{+/+}$vs $\left.H b 9^{\text {cre }} N C A M^{f l x}\right)$. These results suggest that extrasynaptic SV cycling decreases in motoneurons lacking NCAM when L-VDCCs are blocked. To determine whether L-VDCCs are present in axonal sprouts near the synapse where their inhibition might cause changes in neurotransmission, we immunostained $\alpha$-BTX ${ }^{+}$ end plates in $H b 9^{c r e} N C A M^{f l x}$ mice with antibodies against synaptophysin and L-VDCCs. Figure $6 F$ shows a typical sprout near an $\alpha$-BTX ${ }^{+}$end plate in a partially denervated muscle positively labeled for synaptophysin and L-VDCC, consistent with the latter playing a role in vesicle cycling along the axon (see also Polo-Parada et al., 2001). This close association between L-VDCCs and syn ${ }^{+}$puncta in vivo is consistent with similar observations obtained from cultured 
motor neurons derived from embryonic stem cells (Chipman et al., 2014).

\section{Intraperitoneal nifedipine enhances synaptic sprouting in vivo}

Our results show that acute application of an L-VDCC antagonist increases neurotransmission at immature synapses in partially denervated $H b g^{c r e} N C A M^{f l x}$ muscles. Furthermore, nifedipine also decreased the number of cycling vesicles at extrasynaptic sites in partially denervated $H b 9^{\text {cre }} N C A M^{f l x}$ muscles. From these results, we speculated that chronic administration of nifedipine after partial denervation would enhance synapse formation and the recovery of motor force in $H b 9^{c r e} N C A M^{f l x}$ mice. To test this, we administered nifedipine ( $5 \mathrm{mg} / \mathrm{kg}$, i.p., nifedipine daily), or an equal volume of vehicle, to $H b 9^{\text {cre }} N C A M^{f l x}$ mice for 1 week, beginning at $7 \mathrm{~d} \mathrm{pPD} \mathrm{(Fig.} \mathrm{7A).} \mathrm{We} \mathrm{chose} \mathrm{to} \mathrm{start} 7 \mathrm{~d}$ pPD because this time point coincides with the most intense period of synaptogenesis and stabilization. Figure $7 B$ shows typical force profiles, in response to $50 \mathrm{~Hz}$ stimulation for $1 \mathrm{~s}$, of partially denervated soleus muscles from $H b 9^{c r e} N C A M^{f l x}$ mice treated with vehicle (intraperitoneally) or nifedipine (intraperitoneally). The tetanic forces of partially denervated soleus muscles in mice treated with nifedipine were significantly higher than those in vehicle-treated mice $14 \mathrm{~d}$ pPD (Fig. $7 B, C ; p<0.05, t$ test). Furthermore, they were also not significantly different from partially denervated soleus muscles taken from nifedipine-treated $\mathrm{NCAM}^{+/+}$mice (Fig. 7C; $p>0.05, t$ test). This effect was due to improved synaptogenesis, as more end plates were reinnervated in nifedipinetreated $H b 9^{c r e} N C A M^{f l x}$ mice than in those receiving vehicle (Fig. $7 D, E ; p<0.01$, Mann-Whitney rank sum test). Importantly, the number of parent synapses was not different, confirming that the extent of L5 denervation was consistent between groups (Fig. 7E). Together, these findings demonstrate that deficits in functional synaptic sprouting in the absence of presynaptic NCAM can be reversed in vivo by chronic treatment with nifedipine.

\section{Discussion}

Here we demonstrate that motor neurons require NCAM to expand their synaptic territory. The loss of presynaptic NCAM impairs the recovery of muscle function following partial muscle denervation because sprouting motor terminals do not adequately reinnervate denervated synapses. Although some immature synapses formed in $H b 9^{c r e} N C A M^{f l x}$ mice, they fail to develop mature neurotransmission, in part, because synaptic vesicle mobilization is abnormal. Remarkably, the inhibition of a nifedipine-sensitive SV recycling pathway boosts neurotransmission at newly formed synapses in $H b 9^{\text {cre }} N C A M^{f l x}$ mice, and improves reinnervation and muscle function. These findings identify presynaptic NCAMs and L-VDCCs as major regulators of synaptic remodeling in the mouse neuromuscular system.

Partial denervation initiates a series of cellular events that quickly lead to synapse reinnervation and muscle recovery. First, terminal capping Schwann cells (Todd et al., 2010) extend processes from denervated end plates to initiate axonal sprouting (Son and Thompson, 1995; Love and Thompson, 1999). Second, axonal sprouts are guided by Schwann cell bridges to reinnervate denervated synapses (Son and Thompson, 1995), with reinnervation being largely complete after 2 weeks in mouse hindlimb muscles (Brown and Ironton, 1978). Partially denervated cat hindlimb muscles recovery preinjury force values even when $80 \%$ of their motor innervation is destroyed (Rafuse et al., 1992). This recovery occurs because the remaining intact MUs increase in size by four to five times their original values (Rochel and Rob- bins, 1988; Rafuse et al., 1992). Muscle force recovery is incomplete when partial denervation destroys $>80 \%$ of the MUs because motor neurons cannot expand their terminal fields beyond four to five times their original size (Rafuse and Gordon, 1996). The mechanisms underlying this limitation have remained unknown, but results from this study indicate that intrinsic properties of motor neurons are essential (see also Rochel and Robbins, 1988).

Recent studies have shown that SV sharing occurs between synapses in the CNS and PNS (de Paiva et al., 1999; Krueger et al., 2003; Darcy et al., 2006; Staras et al., 2010). Studies at CNS synapses have revealed mobile packets of fusion-competent SVs that likely contribute to functional synaptic plasticity (Staras and Branco, 2010). The mobility of these vesicles can be controlled by several structural scaffolding and signaling molecules, including actin, BDNF, synapsin, and Cdk5 (Darcy et al., 2006; Staras et al., 2010; Orenbuch et al., 2012). Here, we demonstrate that intersynaptic sharing of SVs also contributes to local expansion of MUs following partial muscle denervation and that NCAM is involved in this process. How does presynaptic NCAM influence SV recruitment to synapses? One possibility is that NCAM promotes tethering of SVs to sites of NCAM adhesion. However, a stochastic capture of transiting vesicles, possibly influenced by synaptic activity, is also conceivable, as shown for peptidergic distribution in Drosophila (Shakiryanova et al., 2006; Wong et al., 2012). It is important to mention in this context that the cytoskeleton plays an important role in this tethering, since transiting SVs in CNS neurons is regulated by actin turnover (Darcy et al., 2006). As NCAM binds to the cytoskeleton via spectrin (Leshchyns'ka et al., 2003) and influences synapsin function by activating calcium/calmodulin kinases (Chi et al., 2003; Bodrikov et al., 2008), presynaptic NCAM may also alter the association of SVs with cytoskeletal elements underlying their recruitment to synapses.

Another explanation for the role of the NCAM in SV recruitment may come from seemingly disparate evidence regarding its influence over the SV cycle. NCAMs regulate the maturation from an immature (L-VDCC-dependent) to a mature (L-VDCCindependent) form of SV recycling (Polo-Parada et al., 2001; Hata et al., 2007), and constitutively NCAM-deficient mice exhibit deficits in NMJ neurotransmission when stimulated at high frequency (Polo-Parada et al., 2005). These deficits include periodic transmission failures and enhanced short-term depression, which are characteristic of abnormal SV recycling and are mimicked with inhibitors of myosin light chain kinase (MLCK) and myosin II (Polo-Parada et al., 2001, 2005). Moreover, a relationship exists between different modes of SV endocytosis and SV mobility, which depend on MLCK and myosin II function (Peng et al., 2012). Specifically, SVs retrieved following evoked activity were more mobile and showed more directional bias than those recovered from synapses following spontaneous events. It can therefore be hypothesized that alterations in endocytic mechanisms that persist in the absence of NCAMs lead to abnormal accumulation of SVs that are defective in transport and transit.

At CNS synapses, dynamin inhibition impairs evoked release but not spontaneous release (Chung et al., 2010), suggesting dynamin-mediated endocytosis occurs predominantly as a result of evoked neurotransmission, thus fueling further rounds of exocytosis. In hippocampal cultures and motor neuron/myotubes cocultures, SV recycling at constitutively NCAM-deficient synapses abnormally maintains a prominent dynamin-insensitive component (Shetty et al., 2013; Chipman et al., 2014). If SVs generated by evoked endocytosis (i.e., dynamin mediated) pref- 
erentially associate with myosin II motors and are more highly mobile than those generated by spontaneous activity (Peng et al., 2012; Chandrasekar et al., 2013), it is conceivable that SVs generated in the absence of NCAM (i.e., independently of dynamin) are considerably less mobile than those generated by wild-type neurons because they do not associate with myosin II (PoloParada et al., 2005). Deficits of SV retrieval, in the absence of presynaptic NCAM, may therefore lead to deficits in SV mobility and would become most conspicuous when a high degree of SV mobility is most needed (i.e., during MU expansion).

Interestingly, the $\mathrm{Ca}^{2+}$ channel blocker nifedipine influences SV distribution and recycling, particularly at immature and mutant synapses. Nifedipine potently inhibits L-VDCCs, which are highly expressed by motor neurons (Westenbroek et al., 1998), skeletal muscles (Chen et al., 2011), and Schwann cells (Robitaille et al., 1996). While the effects we observe could be due to the inhibition of L-VDCCs in any of these cell types, a presynaptic action of nifedipine is most likely for several reasons. First, the $m$ value of synaptic transmission was potentiated by nifedipine, demonstrating a presynaptic action. Second, we observed a specific influence of nifedipine on SV recycling, which was also observed by motor neurons cocultured with skeletal myofibers (Chipman et al., 2014). Third, L-VDCC immunolabeling was closely associated with synaptophysin-immunopositive puncta in partially denervated muscles, and it was partially colocalized with NCAM-immunopositive puncta in motor axons grown in vitro (Chipman et al., 2014). Thus, although we cannot rule out the contribution of other cell types to the effects seen with nifedipine, we hypothesize that they are most likely due the action of NCAMs in presynaptic terminals and axons.

Nifedipine has been reported to enhance MU sprouting following partial denervation in wild-type mice (White and Vrbová, 1998). This finding contrasts with our observation that wild-type mice were not affected by the administration of nifedipine following partial denervation. However, while White and Vrbová (1998) implanted nifedipine-impregnated silicone strips $2 \mathrm{~d}$ following partial denervation in the rat, we used intraperitoneal application of nifedipine $7 \mathrm{~d}$ after partial denervation in the mouse. Thus, the differences observed could be due to different experimental protocols, including the timing of drug administration, animal species, conditions of electrophysiological measurements, and others.

While presynaptic NCAM is required for the redistribution of SVs to synaptic sites at expanded terminals, it is not essential for synaptic stabilization following complete nerve transection and NMJ reinnervation (Chipman et al., 2010). This difference is likely due to two factors. First, regenerative programs initiated by complete nerve transection are probably very different from those initiated by uninjured motor neurons extending sprouts (Navarro et al., 2007). Axotomy-induced regenerative programs likely upregulate proteins that provide synaptic stabilization in the absence of presynaptic NCAM. This redundancy likely occurs during development because NMJs in constitutively NCAM-null mice are not inherently unstable (Rafuse et al., 2000). Second, motor neurons in partially denervated muscles sprout and form substantially larger MUs compared with those formed in reinnervated muscles after a nerve crush injury (Rafuse and Gordon, 1996). Enlarged fields of innervation require efficient redistribution of SVs to additional supernumerary NMJs (Rochel and Robbins, 1988), and they also increase metabolic demand due to an overall increase in synaptic transmission (Rangaraju et al., 2014).
Although motor neuron diseases are not known to have NCAM mutations, alterations in SV recycling, mobility, and distribution are observed in mouse models of ALS and likely underlie some aspects of synaptic instability observed early on in the disease (Pun et al., 2006). Such deficits would restrict endogenous repair mechanisms. Furthermore, as motor neuron diseases are known to involve disruptions to $\mathrm{Ca}^{2+}$ homeostasis (Ruiz et al., 2010), treatment with VDCC inhibitors during well defined stages of neurodegeneration may prove beneficial.

\section{References}

Abercrombie M (1946) Estimation of nuclear populations from microtome sections. Anat Rec 94:239-247. CrossRef Medline

Béïque JC, Na Y, Kuhl D, Worley PF, Huganir RL (2011) Arc-dependent synapse-specific homeostatic plasticity. Proc Natl Acad Sci U S A 108: 816-821. CrossRef Medline

Bodrikov V, Sytnyk V, Leshchyns'ka I, den Hertog J, Schachner M (2008) NCAM induces CaMKII-mediated RPTP phosphorylation to enhance its catalytic activity and neurite outgrowth. J Cell Biol 182:1185-1200. CrossRef Medline

Branco T, Staras K, Darcy KJ, Goda Y (2008) Local dendritic activity sets release probability at hippocampal synapses. Neuron 59:475-485. CrossRef Medline

Brown MC, Ironton R (1978) Sprouting and regression of neuromuscular synapses in partially denervated mammalian muscles. J Physiol 278:325348. Medline

Bukalo O, Fentrop N, Lee AY, Salmen B, Law JW, Wotjak CT, Schweizer M, Dityatev A, Schachner M (2004) Conditional ablation of the neural cell adhesion molecule reduces precision of spatial learning, long-term potentiation, and depression in the CAl subfield of mouse hippocampus. J Neurosci 24:1565-1577. CrossRef Medline

Chandrasekar I, Huettner JE, Turney SG, Bridgman PC (2013) Myosin II regulates activity dependent compensatory endocytosis at central synapses. J Neurosci 33:16131-16145. CrossRef Medline

Chattopadhyaya B, Baho E, Huang ZJ, Schachner M, Di Cristo G (2013) Neural cell adhesion molecule-mediated Fyn activation promotes GABAergic synapse maturation in postnatal mouse cortex. J Neurosci 33:5957-5968. CrossRef Medline

Chen F, Liu Y, Sugiura Y, Allen PD, Gregg RG, Lin W (2011) Neuromuscular synaptic patterning requires the function of skeletal muscle dihydropyridine receptors. Nat Neurosci 14:570-577. CrossRef Medline

Chi P, Greengard P, Ryan TA (2003) Synaptic vesicle mobilization is regulated by distinct synapsin I phosphorylation pathways at different frequencies. Neuron 38:69-78. CrossRef Medline

Chipman PH, Franz CK, Nelson A, Schachner M, Rafuse VF (2010) Neural cell adhesion molecule is required for stability of reinnervated neuromuscular junctions. Eur J Neurosci 31:238-249. CrossRef Medline

Chipman PH, Zhang Y, Rafuse VF (2014) A stem-cell based bioassay to critically assess the pathology of dysfunctional neuromuscular junctions. PLoS One 9:e91643. CrossRef Medline

Chung C, Barylko B, Leitz J, Liu X, Kavalali ET (2010) Acute dynamin inhibition dissects synaptic vesicle recycling pathways that drive spontaneous and evoked neurotransmission. J Neurosci 30:1363-1376. CrossRef Medline

Covault J, Sanes JR (1986) Distribution of N-CAM in synaptic and extrasynaptic portions of developing and adult skeletal muscle. J Cell Biol 102:716-730. CrossRef Medline

Darcy KJ, Staras K, Collinson LM, Goda Y (2006) Constitutive sharing of recycling synaptic vesicles between presynaptic boutons. Nat Neurosci 9:315-321. CrossRef Medline

del Castillo J, Katz B (1954a) Quantal components of the end-plate potential. J Physiol 124:560-573. Medline

del Castillo J, Katz B (1954b) Statistical factors involved in neuromuscular facilitation and depression. J Physiol 124:574-585. Medline

Dengler R, Konstanzer A, Küther G, Hesse S, Wolf W, Struppler A (1990) Amyotrophic lateral sclerosis: macro-EMG and twitch forces of single motor units. Muscle Nerve 13:545-550. CrossRef Medline

de Paiva A, Meunier FA, Molgó J, Aoki KR, Dolly JO (1999) Functional repair of motor endplates after botulinum neurotoxin type A poisoning: biphasic switch of synaptic activity between nerve sprouts and their parent terminals. Proc Natl Acad Sci U S A 96:3200-3205. CrossRef Medline 
Enriquez-Barreto L, Palazzetti C, Brennaman LH, Maness PF, Fairén A (2012) Neural cell adhesion molecule, NCAM, regulates thalamocortical axon pathfinding and the organization of the cortical somatosensory representation in mouse. Front Mol Neurosci 5:76. CrossRef Medline

Fischer LR, Glass JD (2007) Axonal degeneration in motor neuron disease. Neurodegener Dis 4:431-442. CrossRef Medline

Franz CK, Rutishauser U, Rafuse VF (2005) Polysialylated neural cell adhesion molecule is necessary for selective targeting of regenerating motor neurons. J Neurosci 25:2081-2091. CrossRef Medline

Franz CK, Rutishauser U, Rafuse VF (2008) Intrinsic neuronal properties control selective targeting of regenerating motoneurons. Brain 131:14921505. CrossRef Medline

Gaffield MA, Betz WJ (2006) Imaging synaptic vesicle exocytosis and endocytosis with FM dyes. Nat Protoc 1:2916-2921. CrossRef Medline

Gorassini M, Eken T, Bennett DJ, Kiehn O, Hultborn H (2000) Activity of hindlimb motor units during locomotion in the conscious rat. J Neurophysiol 83:2002-2011. Medline

Gordon T, Hegedus J, Tam SL (2004) Adaptive and maladaptive motor axonal sprouting in aging and motoneuron disease. Neurol Res 26:174-185. CrossRef Medline

Hata K, Polo-Parada L, Landmesser LT (2007) Selective targeting of different neural cell adhesion molecule isoforms during motoneuron myotube synapse formation in culture and the switch from an immature to mature form of synaptic vesicle cycling. J Neurosci 27:14481-14493. CrossRef Medline

Hegedus J, Putman CT, Tyreman N, Gordon T (2008) Preferential motor unit loss in the SOD1G93A transgenic mouse model of amyotrophic lateral sclerosis. J Physiol 586:3337-3351. CrossRef Medline

Katz E, Ferro PA, Weisz G, Uchitel OD (1996) Calcium channels involved in synaptic transmission at the mature and regenerating mouse neuromuscular junction. J Physiol 497:687-697. Medline

Krueger SR, Kolar A, Fitzsimonds RM (2003) The presynaptic release apparatus is functional in the absence of dendritic contact and highly mobile within isolated axons. Neuron 40:945-957. CrossRef Medline

Leshchyns'ka I, Sytnyk V, Morrow JS, Schachner M (2003) Neural cell adhesion molecule (NCAM) association with PKCbeta2 via betaI spectrin is implicated in NCAM-mediated neurite outgrowth. J Cell Biol 161:625639. CrossRef Medline

Love FM, Thompson WJ (1999) Glial cells promote muscle reinnervation by responding to activity-dependent postsynaptic signals. J Neurosci 19: 10390-10396. Medline

Maeno-Hikichi Y, Polo-Parada L, Kastanenka KV, Landmesser LT (2011) Frequency-dependent modes of synaptic vesicle endocytosis and exocytosis at adult mouse neuromuscular junctions. J Neurosci 31:1093-1105. CrossRef Medline

Martin AR (1955) A further study of the statistical composition on the endplate potential. J Physiol 130:114-122. Medline

McLachlan EM, Martin AR (1981) Non-linear summation of end-plate potentials in the frog and mouse. J Physiol 311:307-324. Medline

Milner-Brown HS, Stein RB, Lee RG (1974) Contractile and electrical properties of human motor units in neuropathies and motor neurone disease. J Neurol Neurosurg Psychiatry 37:670-676. CrossRef Medline

Miniou P, Tiziano D, Frugier T, Roblot N, Le Meur M, Melki J (1999) Gene targeting restricted to mouse striated muscle lineage. Nucleic Acids Res 27:e27-e30. CrossRef Medline

Moscoso LM, Cremer H, Sanes JR (1998) Organization and reorganization of neuromuscular junctions in mice lacking neural cell adhesion molecule, tenascin-C, or fibroblast growth factor-5. J Neurosci 18:1465-1477. Medline

Navarro X, Vivó M, Valero-Cabré A (2007) Neural plasticity after peripheral nerve injury and regeneration. Prog Neurobiol 82:163-201. CrossRef Medline

Orenbuch A, Shalev L, Marra V, Sinai I, Lavy Y, Kahn J, Burden JJ, Staras K, Gitler D (2012) Synapsin selectively controls the mobility of resting pool vesicles at hippocampal terminals. J Neurosci 32:3969-3980. CrossRef Medline

Peng A, Rotman Z, Deng PY, Klyachko VA (2012) Differential motion dynamics of synaptic vesicles undergoing spontaneous and activity-evoked endocytosis. Neuron 73:1108-1115. CrossRef Medline

Polo-Parada L, Bose CM, Landmesser LT (2001) Alterations in transmission, vesicle dynamics, and transmitter release machinery at NCAM- deficient neuromuscular junctions. Neuron 32:815-828. CrossRef Medline

Polo-Parada L, Plattner F, Bose C, Landmesser LT (2005) NCAM 180 Acting via a conserved C-terminal domain and MLCK is essential for effective transmission with repetitive stimulation. Neuron 46:917-931. CrossRef Medline

Pun S, Santos AF, Saxena S, Xu L, Caroni P (2006) Selective vulnerability and pruning of phasic motoneuron axons in motoneuron disease alleviated by CNTF. Nat Neurosci 9:408-419. CrossRef Medline

Rafuse VF, Gordon T (1996) Self-reinnervated cat medial gastrocnemius muscles. I. comparisons of the capacity for regenerating nerves to form enlarged motor units after extensive peripheral nerve injuries. J Neurophysiol 75:268-281. Medline

Rafuse VF, Gordon T, Orozco R (1992) Proportional enlargement of motor units after partial denervation of cat triceps surae muscles. J Neurophysiol 68:1261-1276. Medline

Rafuse VF, Polo-Parada L, Landmesser LT (2000) Structural and functional alterations of neuromuscular junctions in NCAM-deficient mice. J Neurosci 20:6529-6539. Medline

Rangaraju V, Calloway N, Ryan TA (2014) Activity-driven local ATP synthesis is required for synaptic function. Cell 156:825-835. CrossRef Medline

Robitaille R, Bourque MJ, Vandaele S (1996) Localization of L-type $\mathrm{Ca}^{2+}$ channels at perisynaptic glial cells of the frog neuromuscular junction. J Neurosci 16:148-158. Medline

Rochel S, Robbins N (1988) Effect of partial denervation and terminal field expansion on neuromuscular transmitter release and nerve terminal structure. J Neurosci 8:332-338. Medline

Ruiz R, Casañas JJ, Torres-Benito L, Cano R, Tabares L (2010) Altered intracellular $\mathrm{Ca}^{2+}$ homeostasis in nerve terminals of severe spinal muscular atrophy mice. J Neurosci 30:849-857. CrossRef Medline

Schaefer AM, Sanes JR, Lichtman JW (2005) A compensatory subpopulation of motor neurons in a mouse model of amyotrophic lateral sclerosis. J Comp Neurol 490:209-219. CrossRef Medline

Schmied A, Pouget J, Vedel JP (1999) Electromechanical coupling and synchronous firing of single wrist extensor motor units in sporadic amyotrophic lateral sclerosis. Clinical neurophysiology 110:960-974. CrossRef Medline

Schuster CM, Davis GW, Fetter RD, Goodman CS (1996) Genetic dissection of structural and functional components of synaptic plasticity. I. Fasciclin II controls synaptic stabilization and growth. Neuron 17:641654. CrossRef Medline

Searl TJ, Silinsky EM (2003) Phorbol esters and adenosine affect the readily releasable neurotransmitter pool by different mechanisms at amphibian motor nerve endings. J Physiol 553:445-456. CrossRef Medline

Shakiryanova D, Tully A, Levitan ES (2006) Activity-dependent synaptic capture of transiting peptidergic vesicles. Nat Neurosci 9:896-900. CrossRef Medline

Shetty A, Sytnyk V, Leshchyns'ka I, Puchkov D, Haucke V, Schachner M (2013) The neural cell adhesion molecule promotes maturation of the presynaptic endocytotic machinery by switching synaptic vesicle recycling from Adaptor Protein 3 (AP-3)- to AP-2-dependent mechanisms. J Neurosci 33:16828-16845. CrossRef Medline

Siri R, Uchitel OD (1999) Calcium channels coupled to neurotransmitter release at neonatal rat neuromuscular junctions. J Physiol 514:533-540. CrossRef Medline

Son YJ, Thompson WJ (1995) Nerve sprouting in muscle is induced and guided by processes extended by Schwann cells. Neuron 14:133-141. CrossRef Medline

Staras K, Branco T (2010) Sharing vesicles between central presynaptic terminals: implications for synaptic function. Front Synaptic Neurosci 2:20. CrossRef Medline

Staras K, Branco T, Burden JJ, Pozo K, Darcy K, Marra V, Ratnayaka A, Goda Y (2010) A Vesicle superpool spans multiple presynaptic terminals in hippocampal neurons. Neuron 66:37-44. CrossRef Medline

Sugiura Y, Ko CP (1997) Novel modulatory effect of L-type calcium channels at newly formed neuromuscular junctions. J Neurosci 17:1101-1111. Medline

Sytnyk V, Leshchyns'ka I, Delling M, Dityateva G, Dityatev A, Schachner M (2002) Neural cell adhesion molecule promotes accumulation of TGN organelles at sites of neuron-to-neuron contacts. J Cell Biol 159:649-661. CrossRef Medline 
Takamori S, Holt M, Stenius K, Lemke EA, Grønborg M, Riedel D, Urlaub H, Schenck S, Brügger B, Ringler P, Müller SA, Rammner B, Gräter F, Hub JS, De Groot BL, Mieskes G, Moriyama Y, Klingauf J, Grubmüller H, Heuser J, et al (2006) Molecular anatomy of a trafficking organelle. Cell 127:831-846. CrossRef Medline

Tam SL, Archibald V, Tyreman N, Gordon T (2002) Tetrodotoxin prevents motor unit enlargement after partial denervation in rat hindlimb muscles. J Physiol 543:655-663. CrossRef Medline

Todd KJ, Darabid H, Robitaille R (2010) Perisynaptic glia discriminate patterns of motor nerve activity and influence plasticity at the neuromuscular junction. J Neurosci 30:11870-11882. CrossRef Medline

Vitureira N, Letellier M, White IJ, Goda Y (2012) Differential control of presynaptic efficacy by postsynaptic $\mathrm{N}$-cadherin and $\beta$-catenin. Nat Neurosci 15:81-89. CrossRef Medline
Westenbroek RE, Hoskins L, Catterall WA (1998) Localization of $\mathrm{Ca}^{2+}$ channel subtypes on rat spinal motor neurons, interneurons, and nerve terminals. J Neurosci 18:6319-6330. Medline

White CM, Vrbová G (1998) Recovery of rat skeletal muscles after partial denervation is enhanced by treatment with nifedipine. Brain Res 779:125135. CrossRef Medline

Wong MY, Zhou C, Shakiryanova D, Lloyd TE, Deitcher DL, Levitan ES (2012) Neuropeptide delivery to synapses by long-range vesicle circulation and sporadic capture. Cell 148:1029-1038. CrossRef Medline

Yang X, Arber S, William C, Li L, Tanabe Y, Jessell TM, Birchmeier C, Burden SJ (2001) Patterning of muscle acetylcholine receptor gene expression in the absence of motor innervation. Neuron 30:399-410. CrossRef Medline 